
Bodoy1,2,10\#, Manuel Palacín ${ }^{1,2,4 \#}$ of Catalonia, Vic, Spain.

*These authors contributed equally

\title{
Defective SIc7a7 transport reduces systemic arginine availability compromising erythropoiesis and iron homeostasis
}

Fernando Sotillo $^{1^{*}}$, Judith Giroud-Gerbetant ${ }^{1,2^{*}}$, Jorge Couso ${ }^{3}$, Rafael Artuch ${ }^{2,4,5}$, Antonio Zorzano ${ }^{1,6,7}$, Aida Ormazabal2,6,7, Mayka Sanchez ${ }^{8}$, Günter Weiss ${ }^{9}$, Susanna

${ }^{1}$ Institute for Research in Biomedicine Barcelona (IRB Barcelona), Barcelona, Spain; ${ }^{2}$ Centro de Investigación Biomédica en Red Enfermedades Raras (CIBERER), Barcelona, Spain; ${ }^{3}$ Institute of Predictive and Personalized Medicine of Cancer, Badalona, Spain; ${ }^{4}$ Department of Clinical Biochemistry, Hospital Sant Joan de Déu (HSJD), Esplugues de Llobregat, Spain; ${ }^{5}$ Institut de Recerca Sant Joan de Déu, Esplugues de Llobregat, Spain; ${ }^{6}$ Department of Biochemistry and Molecular Biomedicine, University of Barcelona, Barcelona, Spain; ${ }^{7}$ Centro de Investigación Biomédica en Red Diabetes y Enfermedades Metabólicas (CIBERDEM), Spain; ${ }^{8}$ Faculty of Medicine and Health Sciences. Universitat Internacional de Catalunya (UIC), Sant Cugat, Spain; ${ }^{9}$ Department of Internal Medicine II (Infectious Diseases, Immunology, Rheumatology and Pneumology), Medical University of Innsbruck, Innsbruck, Austria; ${ }^{10}$ Department of Biosciences, University of Vic - Central University

Key words: $\mathrm{y}^{+}$LAT1, arginine, iron metabolism, macrophage, red blood cell (RBC) 


\section{ABSTRACT}

28 SIc7a7 encodes for $\mathrm{y}^{+}$LAT1, a transporter of cationic amino acid across the basolateral membrane of epithelial cells. Mutations in SLC7A7 gene give rise to Lysinuric Protein Intolerance (LPI), a rare autosomal recessive disease with wide variability of

31 complications. Intriguingly, $\mathrm{y}^{+} \mathrm{LAT1}$ is also involved in arginine transport in non-

32 polarized cells such as macrophages. Here we report that complete inducible S/c7a7 ablation in mouse compromises systemic arginine availability that alters proper erythropoiesis and that dysfunctional RBC generation leads to increased erythrophagocytosis, iron overload and an altered iron metabolism by macrophages. Herein, uncovering a novel mechanism that links amino acid metabolism to erythropoiesis and iron metabolism. Mechanistically, the iron exporter ferroportin-1 expression was compromised by increased plasma hepcidin causing macrophage iron accumulation. Strikingly, lysozyme M-cell-specific knockout mice failed to reproduce the total knockout alterations, while bone marrow transplantation experiments resulted in the resolution of macrophage iron overload but could not overcome erythropoietic defect. This study establishes a new crucial link between systemic arginine availability in erythropoiesis and iron homeostasis. 


\section{Introduction}

59 Red blood cell (RBC) generation is a tightly regulated process where RBC

60 homeostasis is key for proper iron recycling (de Back et al., 2014). Although extensive work has been done in the field of erythropoiesis, little is known about the impact of amino acid metabolism in this complex process. The mechanisms of RBC generation spans from bone marrow (BM) erythroid differentiation mediated by CD169+ macrophages (Chow et al., 2013), which supports erythroblastic island formation, to the end-final stage where RBC phagocytosis by red pulp macrophages (RPMs) leads to hemoglobin breakdown and ultimately iron recycling and release (Klei et al., 2017). RBC maturation requires specific components to properly coordinate this process. Disruption in hemoglobin synthesis, which comprises one-third of the RBC protein content, leads to altered erythropoiesis (Kuhn et al., 2017; Liu et al., 2013) .Yet, hemoglobin is not the only key component as iron, erythropoietin (EPO), or ferritin are also well known to play essential roles in RBC generation (Beguin, 1998; Goldfarb et al., 2021; Moritz et al., 1997). In terms of metabolic requirements, Shima et al. published the impact of arginine import on erythrocyte differentiation and proliferation throughout the cationic amino acid transporter 1 (CAT1), thereby indicating a crucial role not only of the iron-related components (hemoglobin, EPO, iron and ferritin) but also of metabolites such as arginine in the generation of mature RBCs (Shima et al., 2006). Macrophages also play an important role in RBC enucleation, being thus key for the last step of RBC generation (Lee et al., 2004; Popova et al., 2009; Swartz et al., 2017).

Macrophages are a cell type that participates in diverse biological processes, including host defence and wound repair (Koh and DiPietro, 2011). Nevertheless, further roles for these cells began to emerge with the identification of specific functions of tissue- 
resident macrophages, such as Kupffer cells and splenic RPMs, which are mainly involved in erythrocyte phagocytosis and iron recycling (Beaumont and Delaby, 2009; Ganz, 2012; Theurl et al., 2016), alveolar macrophages (AMs), which participate in both lung development and surfactant recycling, and osteoclasts, which contribute to bone development (Hussell and Bell, 2014; Murray and Wynn, 2011). Interest in macrophages in the context of metabolic disease has gained momentum due to a number of recent findings. Macrophage polarization is well known to be tighly linked to altered cellular metabolism including iron homeostasis and glycolysis/citric acid cycle activity (Recalcati et al., 2012; Stienstra et al., 2017). In addition, changes in Larginine metabolism have been coupled to different immune effector phenotypes of macrophages involved in autoimmunity, infection control and activation (Bronte and Zanovello, 2005; Jha et al., 2015; Weiss and Schaible, 2015). caused by mutations in SLC7A7 gene (solute carrier family 7) which encodes for y+LAT1 (Palacín et al., 2001; Torrents et al., 1999) , a light subunit of the heterodimeric amino acid transporter family. $Y^{+}$LAT1 mediates the exchange of cationic amino acids (CAAs) with neutral amino acids plus sodium (Palacín et al., 2005) across the basolateral membrane of epithelial cells. Mutations in $y^{+}$LAT1 results in defective transport of CAAs, leading to reduced arginine, ornithine and lysine plasma concentration while increased in urine (Ogier de Baulny et al., 2012). Consistent with 103 the clinical manifestations of human LPI, we have previously reported that the 104 inducible complete loss of $\mathrm{y}^{+}$LAT1 in mice leads to hypoargininemia, which results in urea cycle disruption and hyperammonemia. Consequently leading to reduced body weight, brain edema and pulmonary alveolar proteinosis between other complications

107 (Bodoy et al., 2019). In addition, several studies found that patients with one or several 
mutations in S/c7a7 gene have abnormal blood count, as well as microcytic anemia

109 (Alqarajeh et al., 2020; Rajantie et al., 1980). To date, the standard treatment for LPI

110 mainly consists on a low-protein based diet supplemented with oral citrulline

111 (Lukkarinen et al., 2003), where citrulline is intracellularly converted to arginine in renal

112 epithelial cells. Hence, improving the defects in urea cycle and correcting both plasma

113 arginine and ammonia levels (Dhanakoti et al., 1990).

114 Notably, $\mathrm{y}^{+}$LAT1 also mediates arginine transport in non-polarized cells, such as

115 macrophages. Intriguingly, $\mathrm{y}^{+} \mathrm{LAT1}$ was shown to drive major arginine transport in

116 human monocytes after interferon stimulation (Rotoli et al., 2020). Thus, being one of

117 the major arginine transporters in human monocytes, AMs and monocyte-derived

118 macrophages (Barilli et al., 2012).

119 Motivated by the fact that human SLC7A7 mutations give rise to immune and

120 hematological complications, here we questioned whether amino acid transport via

121 S/c7a7 has important roles for erythropoiesis and/or iron homeostasis. Using total

122 loss-of-function of $y^{+}$LAT1, recovery with citrulline, Lysozyme M-cell-specific (i.e. myeloid-specific) knockout mice and BM transplantations, we demonstrated that the systemic metabolic condition of LPI (mainly hypoargininemia and/or hyperammonemia) leads to defective erythropoiesis and altered RBCs, prompting

126 thus increased erythrophagocytosis ultimately leading to highly iron loaded RPMs and

127 BMMs and hyperferritinemia. Mechanistically, depletion of extracellular arginine and 128 increased plasma amonia levels, as a result of S/c7a7 ablation in kidney and intestine, 129 leads to impared development of RBCs that are more phagocyted by RPMs. Iron 130 overload is a well known hepcidin driver through the bone morphogenic protein -6 131 (BMP6) (Andriopoulos et al., 2009), hence, high levels of iron triggered hepcidin 132 expression which in turn downregulated FPN1 in Slc7a7 macrophages, by this way 
altering iron recycling. Further analyses revealed that defective erythropoiesis was absent in the myeloid-specific knockout mouse. These findings connect two previously unrelated biological processes, namely defective RBC generation and macrophage

136 iron accumulation, and implicate the LPI metabolic derangement as a key player in the

137 hematologic complications of the disease.

\section{Results}

139 Global $\mathbf{y}^{+}$LAT1 ablation in adult mice results in a drastic reduction of bone

140 marrow macrophages and red pulp macrophages.

$141 \mathrm{Y}^{+}$LAT1 is highly expressed in epithelial cells and in some non-polarized cells such as macrophages (Pollard, 2009; Rotoli et al., 2020). To dissect the role of $\mathrm{y}^{+}$LAT1 in the

143 immune and hematological complications of LPI, we created a $\mathrm{y}^{+}$LAT1 conditional 144 allele $\left(S / c 7 a 7^{\text {loxp/+}}\right)$ and generated a S/c7a $7^{\text {loxp/loxp/UBC-Cre+ }}$ inducible knockout model

145 that expresses Cre in all the body cells in response to tamoxifen treatment. Twelve146 week-old $S / c 7 a 7^{\text {loxp/loxp/UBC-Cre+ }}\left(S / c 7 a 7^{--}\right.$, after tamoxifen induction) mice and their

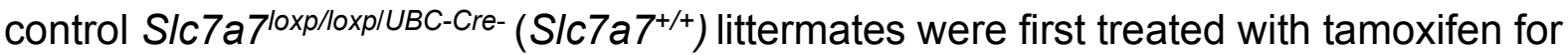

1487 days to induce Cre expression and were further kept on low-protein diet. As a result,

$149 \mathrm{y}^{+}$LAT1 depletion led to significant reduction of spleen weight (Figure 1A). However,

150 consistent with previous reports that citrulline administration ameliorates

151 hypoargininemia and hyperammonemia as well as the vast majority of the defects caused by $\mathrm{y}^{+}$LAT1 ablation (Bodoy et al., 2019), 10 days of citrulline supplementation also improved spleen weight (Supplementary Figure 1A). Of note, Slc7a7 ablation led

154 to lower levels of F4/80-positive cells in spleen and BM sections, together with a 155 reduced number of $\mathrm{F} 4 / 80^{\mathrm{hi}} \mathrm{cd} 11 \mathrm{~b}^{\text {lo }}$ cells in vivo (Figure $1 \mathrm{~B}-\mathrm{C}$ ), which were also 156 recovered by citrulline administration (Supplementary Figure 1B-C). Besides, 
circulating monocytes levels were also decreased in $\mathrm{y}^{+} \mathrm{LAT} 1-$ deficient mice, thereby

158 indicating a loss of macrophage precursors (Figure 1D).

159 We then asked whether the decreased number of RPMs was associated with a 160 reduced proliferation or increased apoptosis. To this end, we assessed Ki67 and

161 caspase-3 expression in spleen sections. Indeed, Ki67 was reduced in the red pulp area of Slc7a7-/- mice, where RPMs reside (Figure 1E). Moreover, Slc7a7-/ RPMs expressed higher levels of active caspase-3 compared with those of control mice

164 (Figure 1F). Taken together, our data suggests that $\mathrm{y}^{+} \mathrm{LAT1}$ participates in the 165 homeostasis of BMMs and RPMs, which might be caused by both increased apoptosis 166 and decreased levels of proliferation.

$y^{+}$LAT1 deficiency in myeloid cell line does not reproduce conditional knockout mice deficiencies.

170 We then asked whether the lack of S/c7a7 expression in macrophages was key for the

171 defects previously observed (Figure 1 A,C). For that purpose, we generated a myeloid 172 cell-specific knockout mouse (Slc7a7loxp/lox LysM-Cre+; Slc7a7LysM-/-) in which Cre expression is specifically restricted to the myeloid cell lineage. Likewise, the inducible knockout mice, Slc7a $7^{\text {LysM }}$, showed a reduced expression of S/c7a7 in RPMs, AMs and BMDMs (Supp Figure 2A-B). Nevertheless, contrary to the inducible model

176 Slc7a7 $^{--}$(Bodoy et al., 2019), S/c7a7 ${ }^{\text {LysM }}$ mice did not present reduction of $\mathrm{y}^{+}$LAT1 177 expression in kidney, hypoargininemia or urea cycle dysfunction (e.g., increased orotic acid in urine), nor did they show a reduction in spleen size or body weight or a decrease in RPMs and BMMs numbers in vivo (Supp Figure 2B-G). These findings rule out the possibility that the defect comes from the lack of $y^{+}$LAT1 expression in the

181 myeloid cell line and embraces the possibility that systemic reduction of arginine along 
with other unbalanced amino acids and metabolites (LPI systemic metabolic condition) might underlie the observed decrease in macrophage generation and survival in total

184 knockout mice.

SIc7a7-/ but not SIc7a7LysM red pulp macrophages, have a dysfunctional iron metabolism.

188 Since one of the main functions of RPMs is to regulate erythrocyte degradation and 189 iron delivery for erythropoiesis (Kohyama et al., 2009), we next focused on whether 190 iron metabolism was compromised in both mouse models. S/c7a7-/- mice showed a 191 dramatic iron accumulation in the BM and spleen. In contrast, abnormal iron 192 accumulation was not visible in $S / c 7 a 7^{L y s M}$ animals (Figure 2A), thus, further confirming the premise that $\mathrm{y}^{+}$LAT1 deficiency in the myeloid cell line does not cause macrophage dysfunction. Citrulline treatment improved iron accumulation in the spleen and BM in Slc7a7-/- mouse (Figure 2A). In line with this finding, iron content in

196 the liver and spleen tissue were higher in the S/c7a7-/- mice compared to its control

197 littermates and were rescued by citrulline supplementation (Figure 2B).

We next addressed whether iron accumulation in tissues would also be reflected into higher serum ferritin levels (Cohen et al., 2010), a trait usually reported in LPI patients

200 (Ogier de Baulny et al., 2012). Hyperferritinemia was found in the Slc7a7 knockout 201 mice (Figure 2C), and, as expected, the impairment was reversed by citrulline 202 administration and no differences were observed in the Slc7a $7^{L y s M}$ mouse model 203 (Figure 2C). To study whether hyperferritinemia was associated with increased 204 inflammation (Kawasumi et al., 2014; Rosário et al., 2013), we examined IL6 plasma 205 levels. Strikingly, control and S/c7a $7^{--}$mice showed similar levels of IL6 (Supp Figure 206 3A), excluding thereby systemic inflammation as a plausible cause of increased 

tested whether the observed iron accumulation was directly linked to macrophages.

210 Of note, within the spleen, iron accumulation was specifically located in the resident

211 RPMs (Figure 2D).

212 As a whole, these results indicate that the systemic metabolic conditions of LPI cause

213 detrimental effects on RPM homeostasis but S/c7a7 expression in macrophages is not

214 required for the iron accumulation in tissue.

\section{Slc7a $7^{-/}$mouse model show reduced expression of FPN1 in macrophages}

217 To gain insight into how iron is accumulated in macrophages, we analyzed the

218 expression of FPN1, the only known iron exporter, and its relationship to circulating

219 concentrations of hepcidin, the major iron-regulatory hormone that interacts directly

220 with FPN1 triggering its degradation (Nemeth et al., 2004). Of note, hepcidin plasma

221 levels were increased in S/c7a $7^{--}$mice (Figure 3A) which were paralleled by increased expression levels of liver hepcidin (Hamp1) in SIc7a7-/- mice as compared to control littermates (Figure 3B). Hepcidin levels can be regulated at the transcriptional levels by several factors such as inflammation and hepatocyte iron deposits(Sebastiani et al., 2016) . In this regard, microarray data on sorted RPMs from Slc7a7 ${ }^{+/+}$and Slc7a7 /- mouse showed decreased expression of inflammatory-related pathways. Moreover, as indicated above, plasma interleukin 6 levels showed similar levels between both genotypes, thus ruling out the possibility of inflammation as a plausible cause for increased hepcidin levels (Supplementary Figure 3A-B). Nevertheless, enhanced

230 Pearl's Prussian blue staining revealed that S/c7a7-/ liver sections showed specific

231 localization of iron deposits in hepatocytes (Figure 3C), suggesting thus iron 
accumulation as the main cause for increased hepcidin levels. The increased number

233 of iron deposits was accompanied by a significant increase of the BMP6 (Figure 3D),

234 a protein known to interact with hemojuvelin to further (Core et al., 2014), trigger

235 Hamp1 transcription and expression (Andriopoulos et al., 2009; JL et al., 2006). Thus,

236 further supporting the premise that hepatocyte liver accumulation triggers increased

237 hepcidin plasma levels.

238 Flow cytometry analysis revealed a decreased number of FPN1-positive RPMs in

239 S/c7a $7^{-/}$compared to wildtype mice (Figure 3E). Moreover, decreased FPN1

240 expression in RPMs was also confirmed by western blot, where S/c7a7-/- mice show

241 reduced levels of FPN1 in total spleen (Figure 3F).

242 Together, our results indicate that S/c7a7 expression is necessary to maintain proper

243 FPN1 expression and that its imbalance leads to an aberrant iron retention in resident

244 macrophages.

\section{Slc7a7 ${ }^{-/}$mice show exacerbated erythrophagocytosis}

247 Our findings that S/c7a7 ${ }^{-/-}$RPM were loaded with iron together with the imbalance on

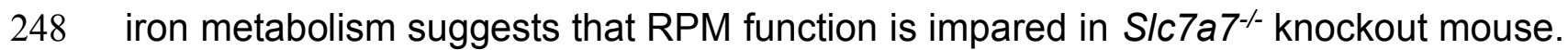

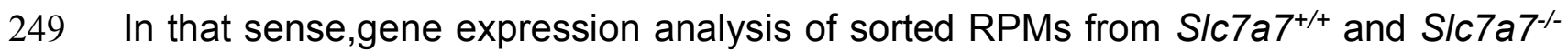

250 animals revealed altered expression of key RPM-associated genes (Figure 4A)

251 (Haldar et al., 2014; Kohyama et al., 2009) further supporting an impaired RPM

252 functioning and disrupted iron handling. Moreover, RPMs are a highly specialized erythrophagocytic cell type in which several genes have been proposed as master

254 regulators of iron homeostasis and RBC clearance (Kohyama et al., 2009). In this regard, these animals showed increased expression of SpiC, the master regulator of

256 RPM differentiation, Msr1, the macrophage scavenger receptor 1, and the hemoglobin 
scavenger receptor $C D 163$ in $S / c 7 a 7^{-/}$mice, while $/ 11 b$ gene expression, a

258 proinflammatory cytokine linked to erythrophagocytosis (A-Gonzalez et al., 2017; Guo

259 et al., 2019; Kohyama et al., 2009; Oexle et al., 2003), was significantly reduced

260 (Figure 4B) (Moestrup and Møller, 2004). This expression pattern suggested an

261 increased erythrophagocytosis activity in S/c7a $77^{-/}$mice. To examine this effect in

262 further detail, we measured the ertyrhophagocytosis ratio of BMDMs from wildtype and

263 knockout mouse. Strikingly, when S/c7a $7^{-/}$and control RBCs were co-incubated with

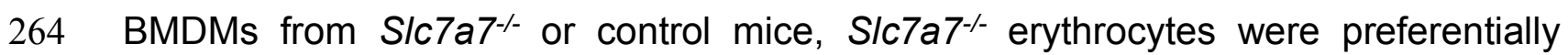

265 engulfed by both macrophages (Figure 4C). Hence, ex vivo experiments confirmed a

266 significantly higher phagocytosis rate of RBCs derived from S/c7a7-- deficient mice

267 compared to RBCs from control animals. In addition, RBCs from S/c7a $7^{-/-}$and control

268 animals treated with citrulline were equally engulfed by both macrophages,

269 demonstrating again the rescuing effect of citrulline (data not shown). These results

270 indicate that the observed iron accumulation in macrophages is due to a defect on the

271 RBCs rather than an alteration on the RPMs functioning.

272

\section{$y^{+}$LAT1 depletion results in defective erythropoiesis}

274 To understand the mechanisms underlying the defect in erythrocytes that results in

275 increased erythrophagocytosis (Figure 4B), we performed a hematological analysis of

276 S/c7a $7^{-/}$animals and its control littermates. S/c7a7 $7^{-/-}$erythrocytes had a reduced mean

277 corpuscular volume (MCV) and hemoglobin $(\mathrm{MCH})$ as well as a decreased mean

278 platelet volume (MPV), while no differences were found in S/c7a7 ${ }^{L y s M}$ mice (Figure 5A-

279 F). Interestingly, erythropoietic progenitors analyzed by flow cytometry showed that

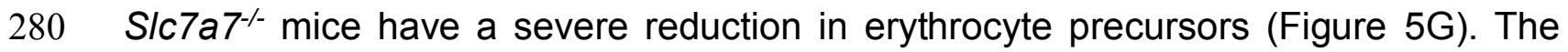

281 dramatic decrease in erythroid precursors implies that LPI systemic metabolic 
282

283

284

condition caused by global S/c7a7 ablation compromises RBC generation. In fact, erythroid precursors of S/c7a $7^{L y s M}$ mice were not affected (Figure $5 \mathrm{G}$ ).

EPO is a secreted hormone responsible for stimulating RBC production and survival. Specifically, EPO has been described to stimulate RBC generation at the proerythroblast stage (Hattangadi et al., 2011). We therefore measured EPO plasma levels and found that, indeed, EPO levels were significantly decreased in S/c7a7-/mice (Figure $5 \mathrm{H}$ ). As a whole, these results indicate that $\mathrm{y}^{+}$LAT1 plays a specific role in erythroid development at multiple proerythroblast stages, possibly orchestrated by the metabolic defects caused by S/c7a7 ablation.

\section{Bone marrow transplant improves iron accumulation but not the metabolic}

\section{complications and erythropoietic defects}

Since immature erythroid precursors were dramatically reduced in $S / c 7 a 7^{-1-}$ mice (Figure 5G), RBCs had an altered MCV and MCH (Figure 5D-E), and S/c7a7tysM animals did not show any erythropoietic defects (Figure 5A-G), we speculated that the observed alterations in the SIc7a7\%- background could be due to the modified systemic microenvironment rather than a cell-autonomous defect in the BM. For this purpose, BM cells isolated from S/c7a $7^{+/+}$mice $(C D 45.1)$ were harvested and transplanted into

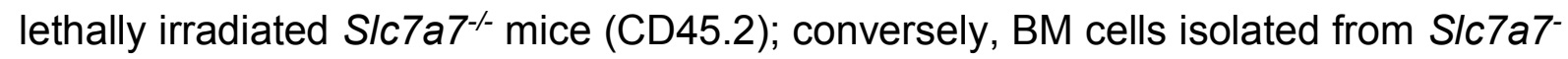
/ mice (CD45.2) were harvested and transplanted into lethally irradiated S/c7a $7^{+/+}$ mice (CD45.1). Five weeks after transplantation, mice were placed on a tamoxifen diet for 7 days and then further fed a low-protein diet for 10 days prior to the sacrifice day (Figure 6A). In this setting, BM transplantation did not improve the body and spleen

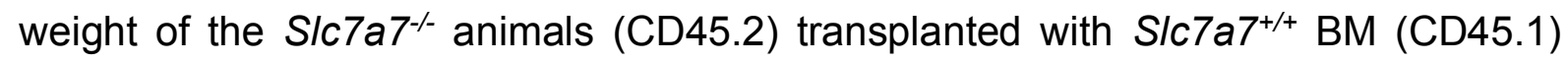
(Figure 6B-C). Analysis of peripheral blood revealed that arginine plasma levels were 
diminished and orotic acid levels in urine were high as a consequence of the urea cycle dysfunction (Figure 6D-E). Thus, as expected, BM transplant did not affect the

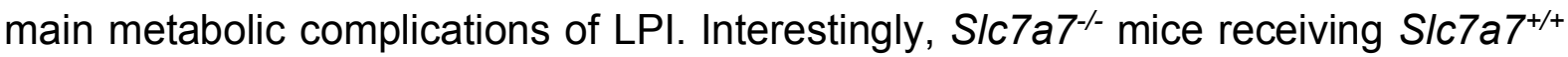

$310 \mathrm{BM}$, did not present iron accumulation in the spleen nor differences in the MCH (Figure

$3116 \mathrm{~F}, \mathrm{~J}$ ) and exhibited a tendency towards lower plasma ferritin levels (Figure 6G). This

312 finding thus indicates that BM transplant can specifically rescue iron metabolism

313 defects. Conversely, S/c7a $7^{-/}$transplanted mice exhibited a vast decrease in erythroid

314 progenitors I-IV compartments together with reduced MCV (Figure $6 \mathrm{H}$ ), reaffirming the

315 profound systemic effect of $\mathrm{y}^{+}$LAT1 deficiency on RBC generation and homeostasis.

\section{Discussion}

319 The $\mathrm{y}^{+}$LAT1 transporter is a cationic/neutral amino acid exchanger that provides arginine for different processes in the organism. Proper arginine availability is essential

321 for a normal urea cycle (Morris, 2002). The defiency of $y^{+}$LAT1 transporter in LPI condition, causes systemic hypoargininemia, which due to the shortage of urea cycle intermediates, results in hyperammonemia (Bodoy et al., 2019). In our mouse model of LPI, as shown here, this metabolic derrangement causes erythropoiesis failure, whereas $\mathrm{y}^{+}$LAT1 expression in macrophages is not enough to cause impared development of RBCs in the Slc7a7 $7^{L y s M}$ mouse model. In this regard, little is known about the role of amino acid availability in erythropoiesis. The impact of L-arginine in erythrocytes is highlighted by the fact that ablation of the arginine transporter CAT1 in mouse results in perinatal death and anemia (Perkins et al., 1997) and that L-argininemediated CAT1 transport participates in erythrocyte differentiation and proliferation in

331 vitro (Shima et al., 2006). Moreover, the L-arginine catalytic enzyme endothelial nitric 
332 oxide synthase (eNOS) can be found in erythrocytes, where parasite-arginine

333 deprivation decreases deformability of these cells as a result of reduced NO

334 production (Cobbold et al., 2016). Here we show that upon ablation of S/c7a7 in all

335 cells, erythrocytes present reduced mean corpuscular volume and mean corpuscular

336 hemoglobine, which has also been also described in LPI patients (Al-Qattan et al.,

337 2021). Since arginine is the metabolite recovered by citrulline administration, we

338 hypothesized that hypoargininemia plays a key role in erythropoiesis and RBC size.

339 Altered RBCs in S/c7a7-- leads to increased erythrophagocitosis. Furthermore, bone

340 marrow-derived macrophages from $y^{+}$LAT1 knock out mice did not show an increased

341 rate of erythrophagocytosis when exposed to control erythrocytes, further supporting

342 that the observed abnormalities in S/c7a7 ${ }^{-/}$RPMs (i.e. increased markers of

343 erythrophagocytosis) are primed by altered erythrocytes rather than by a cell-

344 autonomous defect of RPMs.

345 RPMs prime erythrocyte degradation and iron recycling, and defects in numerous

346 pathways can lead to iron overload in macrophages (Knutson et al., 2005). Such

347 pathological conditions can thus lead to compromised iron metabolism and have an

348 impact on macrophages (Ganz, 2012; Soares and Hamza, 2016). For instance, aged

349 or damaged erythrocytes can express "eat me" signals and acutely trigger the

350 erythrophagocytosis machinery (Luo et al., 2016; Oldenborg, 2000; Park and Kim,

3512017 ) subsequently causing iron accumulation in RPMs (Dichtl et al., 2018) as we

352 clearly observed in the S/c7a $7^{-/-}$model. We postulate therefore that defective arginine

353 availability is also at the basis of iron accumulation because citrulline administration

354 recovers normal iron levels in liver, spleen and BM, and they are also not present in

355 Slc7a $7^{L y s M}$ tissues. 
356 FPN1 is the only known iron exporter involved in iron efflux in macrophages.

357 Mechanistically, FPN1 is regulated at the protein level by hepcidin, which mediates its

358 degradation (Drakesmith et al., 2015). In this regard, the increased hepatic iron

359 content and ferritin levels (Nemeth and Ganz, 2009) would be at the root of induced

360 hepcidin expression as depicted by increased BMP6 liver mRNA expression. As a 361 consequence of increased plasma hepcidin, Slc7a7 ${ }^{-/}$show decreased FPN1 expression in RPMs, which was further confirmed by both flow cytometry and western blot analysis. Presumably, in this LPI mouse model the dysfunctional RBC generation

364 increases erythrophagocytosis by a mechanism that, at the same time, leads to 365 overwork of the fewer RPMs and disrupted iron handling by altered FPN1 366 homeostasis.

367 Erythroblast differentiation is orchestrated mainly by EPO expression (Jelkmann, 2011; Moritz et al., 1997). Our findings that Slc7a7-/- mice show reduced EPO in 369 circulation, highlights the importance of S/c7a7-mediated systemic arginine 370 availability. However, while BM transplant failed to rescue the hematological alterations, it did recover macrophage iron accumulation, suggesting thus two additive mechanisms. On one hand defects in RBC maturation are caused by an unbalanced systemic metabolic environment rather than by a cell-autonomous defect. On the other hand, macrophage iron accumulation also requires Slc7a7 ablation in macrophages. Future work is needed to elucidate the link between Slc7a7-mediated systemic arginine availability and EPO production, and between macrophage $\mathrm{y}^{+}$LAT1 and FPN1 expression.

378 Substantial advances in the research field of LPI have been scarce during the last 379 decade, which can be probably explained by the huge phenotypic variability found 380 among LPI patients (Al-Qattan et al., 2021; Ogier de Baulny et al., 2012; Posey et al., 
381 2014). In a previous work we showed that the inducible total Slc7a7-/ mouse model

382 recapitulates the main hallmarks of the human LPI complications, such as

383 hypoargininemia, hyperammonemia and PAP (Bodoy et al., 2019; Ogier de Baulny et

384 al., 2012; Parto et al., 1994). In the current work we show that S/c7a7-/- mouse model

385 has increased erytrophagocitosis, elevated serum ferritin, altered hemogram and 386 abnormal iron retention in macrophages (Ogier de Baulny et al., 2012). Moreover, the 387 systemic metabolic condition of LPI is an essential driver for the hematologic 388 complications. In addition, S/C7a $7^{-/-}$mice showed deficient erythropoyesis, a trait that 389 paralels the reduced number of reticulocytes in some LPI patients, an alteration that

390 has not been fully explored (AI-Qattan et al., 2021). Our results shifted the spotlight of

391 increased erythrophagocytosis by abnormally functioning macrophages to altered erythrocytes.

393 Historically, systemic metabolic condition and immune-hematologic complications of

394 LPI have been considered as independent entities, such is the case that some authors

395 concerned about a potential detrimental effect of citrulline treatment in the 396 development of immune complications (Ogier de Baulny et al., 2012). Nevertheless, more recently low argininemia was revealed as a poor prognosis factor in LPI (Mauhin

398 et al., 2017). Now, our work upholds the premise that the handling of the metabolic 399 derangements could prove beneficial not only for the metabolic hallmarks of the 400 diseases but also for the reported hematologic complications of the patients.

401

\section{Author Contributions}

403 F.S., J.G., and S.B. designed and performed experiments, interpreted and analyzed 404 data. J.G., S.B., and M.P. designed research and wrote the manuscript with input from 
405 all of the authors. J.C. performed research. G.W and M.S. provided reagents and

406 provided intellectual input. A.O., R.A. and A.Z. provided reagents.

407 The authors declare no competing financial interests.

408 Correspondence: Susanna Bodoy, Institute for Research in Biomedicine Barcelona,

409 Baldiri Reixac, 12, Barcelona 08028, Spain; e-mail:

410 susanna.bodoy@irbbarcelona.org; Manuel Palacín, Institute for Research in

411 Biomedicine Barcelona, Baldiri Reixac, 12, Barcelona 08028, Spain; e-mail:

412 manuel.palacin@irbbarcelona.org.

413 Acknowledgements

414 This work was supported by grants from the Spanish Ministry of Science and 415 Innovation (grant SAF2015-64869-R-FEDER and RTI2018-094211-B-100), Ramon

416 Areces Fundation (I.O.F.R.ARECES) and the Generalitat de Catalunya (grant 2017

417 SGR 961). Grant RTI2018-101735-B-I00 from the Spanish Ministry of Science and 418 Innovation to MS. The EMBO Short Term Fellowship Program facilitated the 419 collaboration between international groups. We are also grateful to Dr. Angel Nebreda 420 at the IRB Barcelona, Spain, for LysM-Cre transgenic mice; Dra Anna Bigas from 421 IMIM, Spain, for CD45.1 mice. We thank Jorge Seco and Vanessa Hernández for 422 technical assistance and help with the experimental animals, and the Daniel Bravo 423 Foundation for support with amino acid determination. 
Figurbio Rxiv preprint doi: https://doi.org/10.1101/2021.08.15.456393; this version posted August 16, 2021. The copyright holder for this preprint Figure (which was not certified by peer review) is the author/funder, who has granted bioRxiv a license to display the preprint in perpetuity. It is made available under aCC-BY 4.0 International license.

A

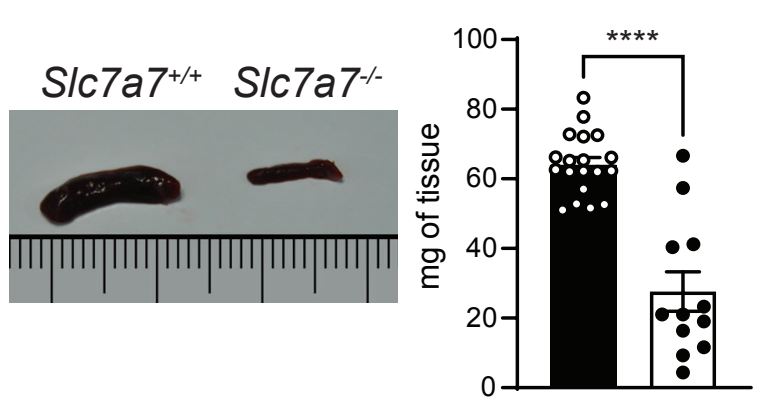

C
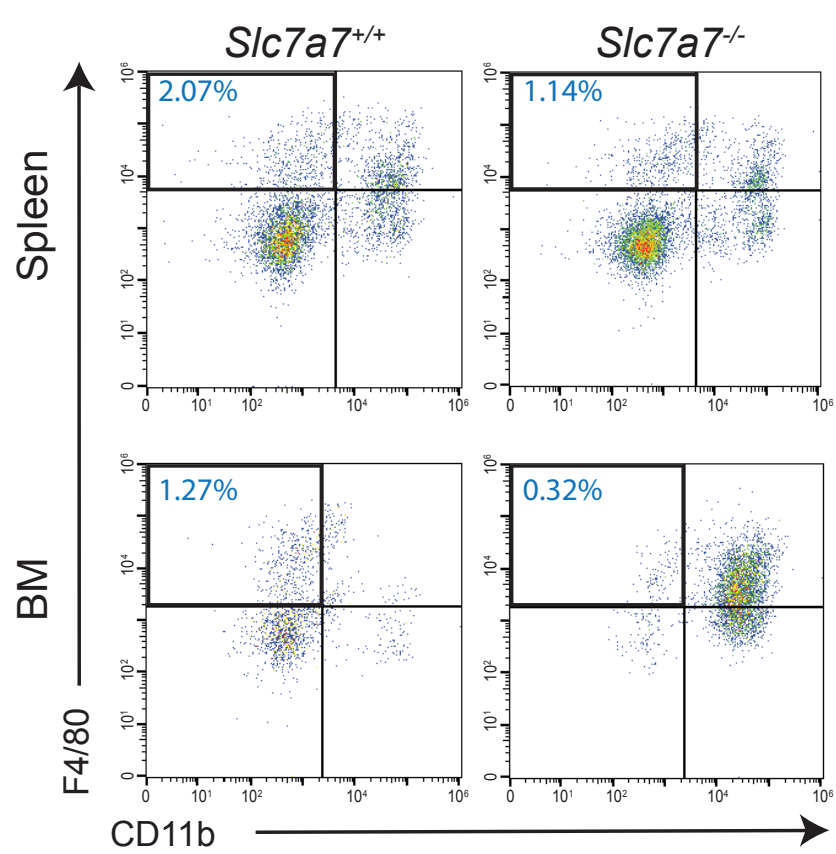

E

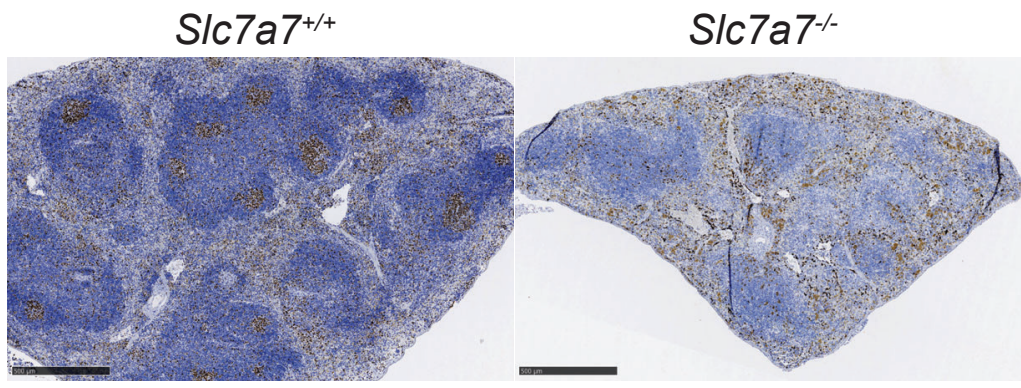

$\mathbf{F}$

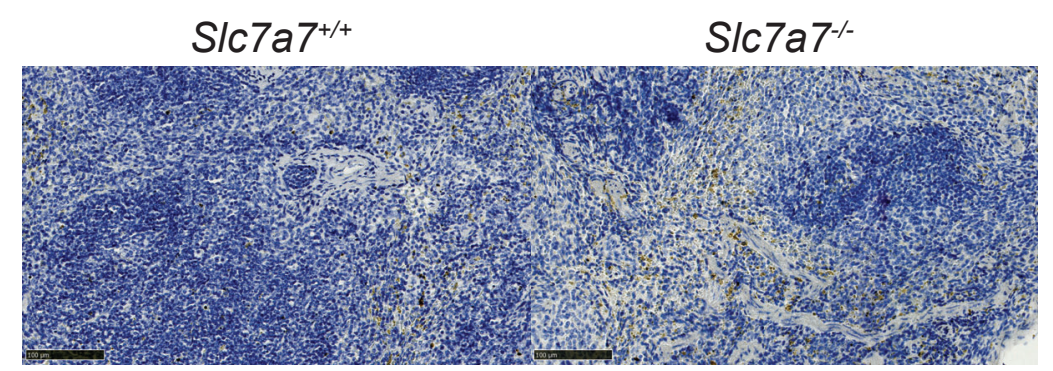

B

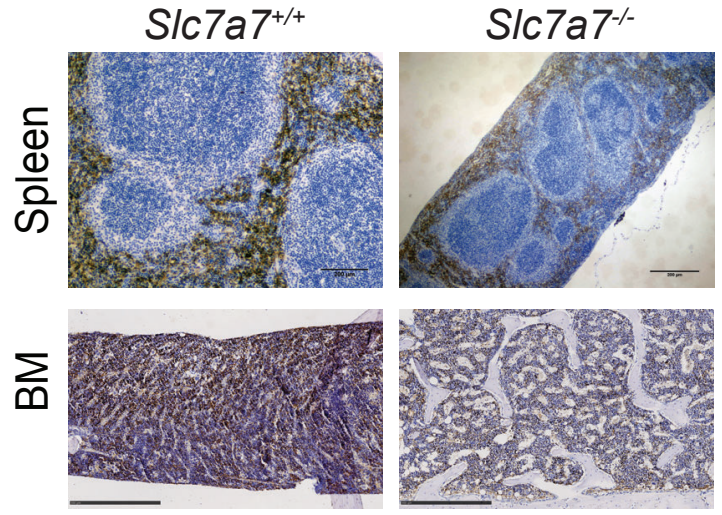

Spleen

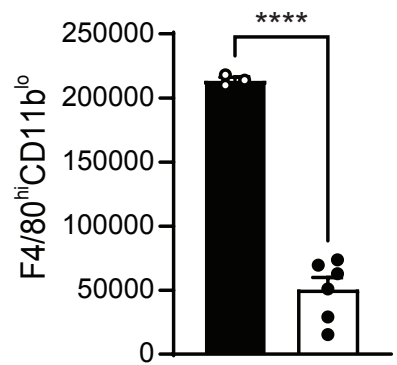

D Monocytes

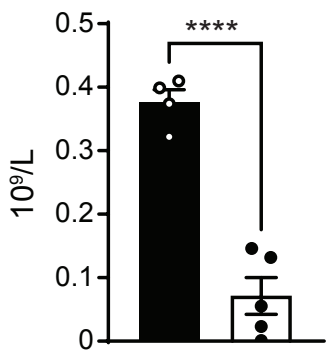

BM

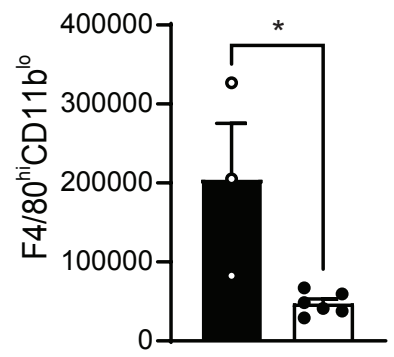

\section{Ki67}

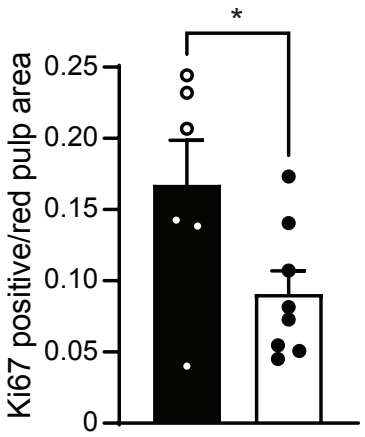

Caspase-3

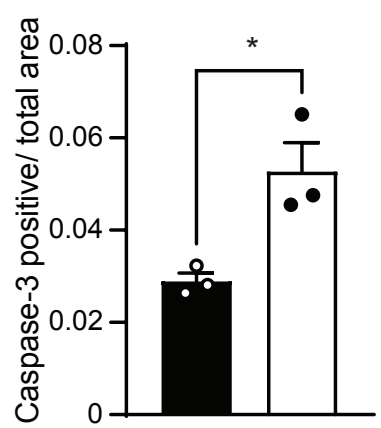



and RPMs. (A) S/c7a7-/- mice and its control littermates were dissected, and spleens were photographed (left panel). Spleen weights are indicated on the right panel. (B) Representative immunohistochemistry staining of $\mathrm{F} 4 / 80^{+}$cells in the spleen and bone marrow (BM) from S/c7a $7^{+/+}$and S/c7a $7^{-/}$animals. Spleen scale bar, $200 \mu \mathrm{m}$, bone marrow scale bar, $500 \mu \mathrm{m}$. (C) Flow cytometry quantification of total number of red pulp macrophages per spleen and bone marrow macrophages per femur and tibia (CD11b $\left.\mathrm{b}^{\mathrm{lo}}, \mathrm{F} 4 / 80^{\mathrm{hi}}\right)$. (D) Comparison of peripheral blood concentration of circulating monocytes levels. (E) Representative Ki67 staining of spleen of Slc7a7 $7^{+/+}$and Slc7a7I- mice (left) and its quantification (right). Scale bar, $500 \mu \mathrm{m}$. (F) Representative Active

440 Caspase-3 staining of spleen of $S / c 7 a 7^{+/+}$and S/c7a $7^{-/}$mice (left) and its quantification

441 (right). Scale bar, $100 \mu \mathrm{m}$. Data are mean \pm SEM. ${ }^{*} P \leq 0.05,{ }^{* * *} P \leq 0.001,{ }^{* * * *} P \leq$ 
bioRxiv preprint doi: https://doi.org/10.1101/2021.08.15.456393; this version posted August 16, 2021. The copyright holder for this preprint

(which was not certified by peer review) is the author/funder, who has granted bioRxiv a license to display the preprint in perpetuity. It is

A

Spleen

BM
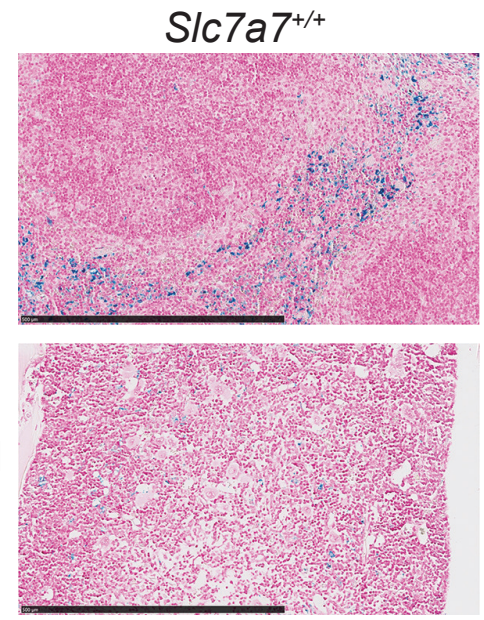

B

Spleen

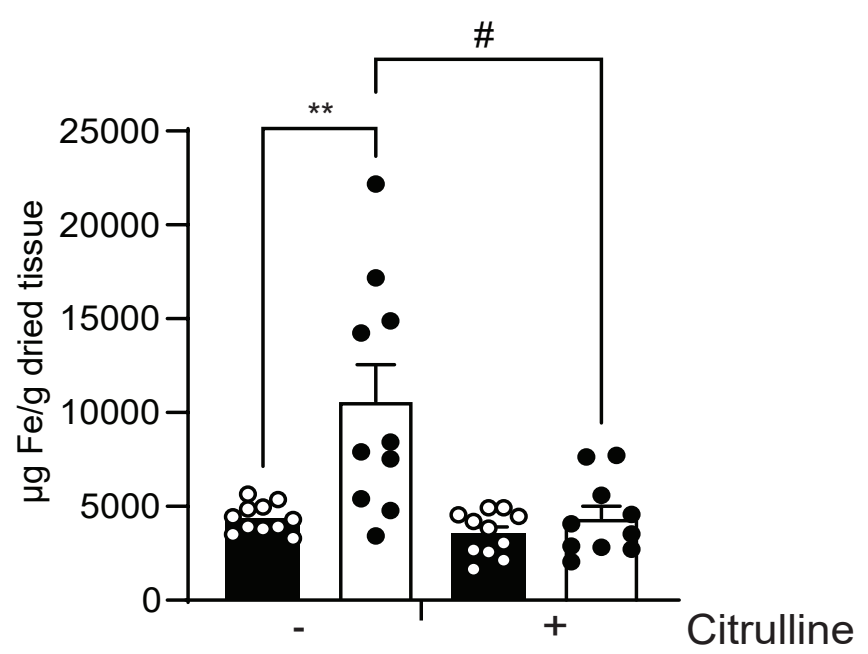

C

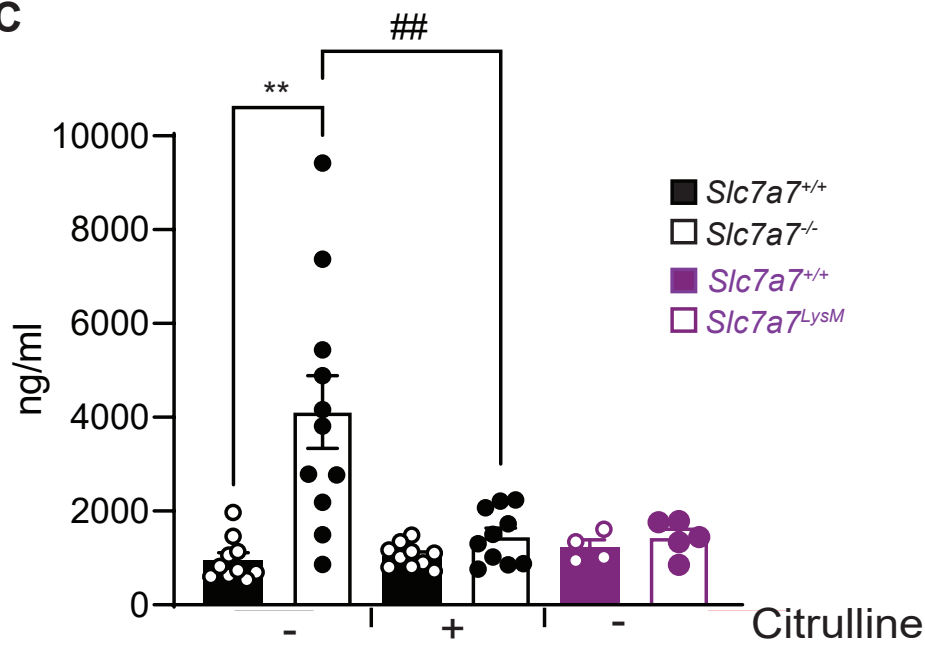

Slc7a7LysM
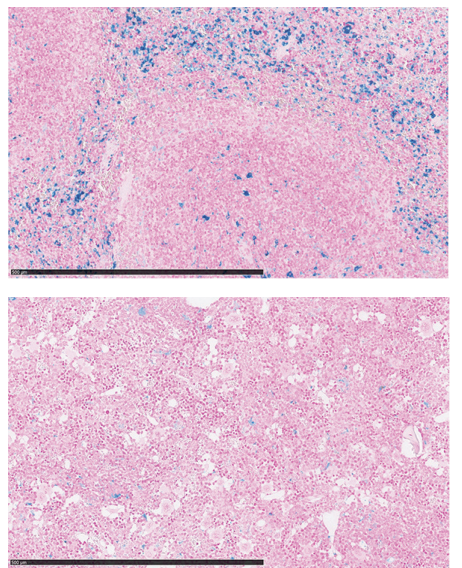

D
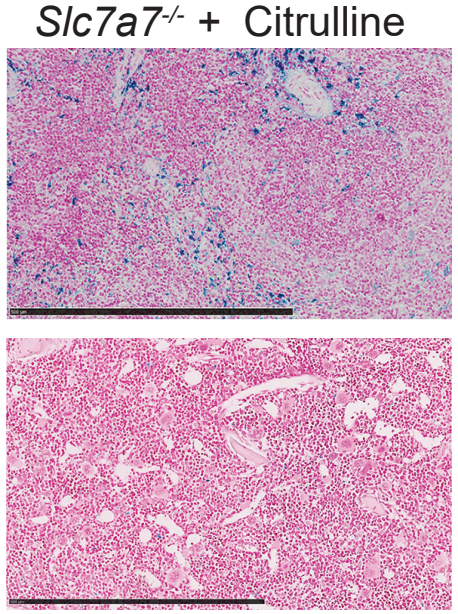

Liver

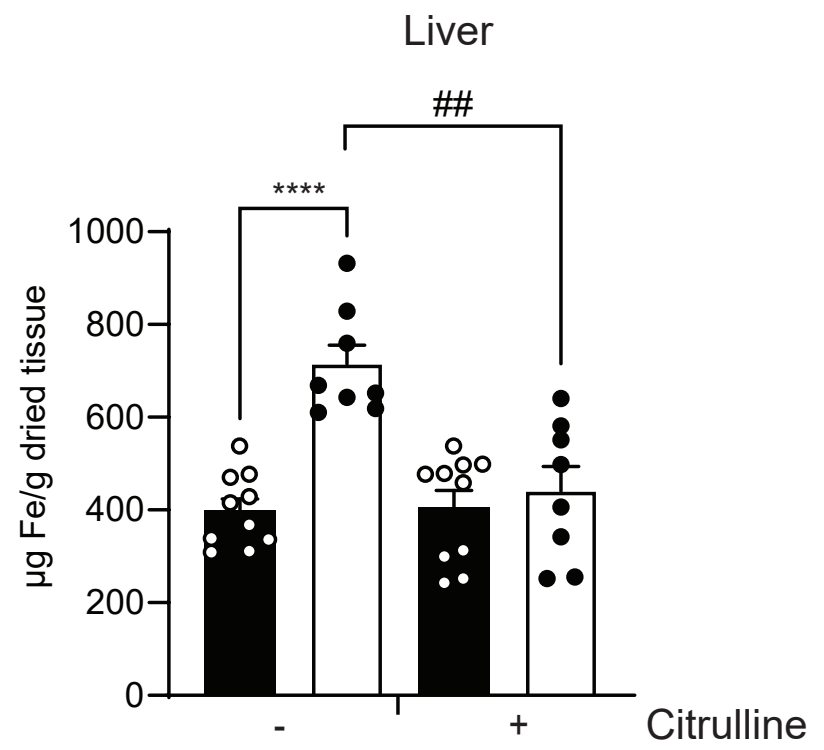
Slc7a $7^{+/+}$ Slc7a7-

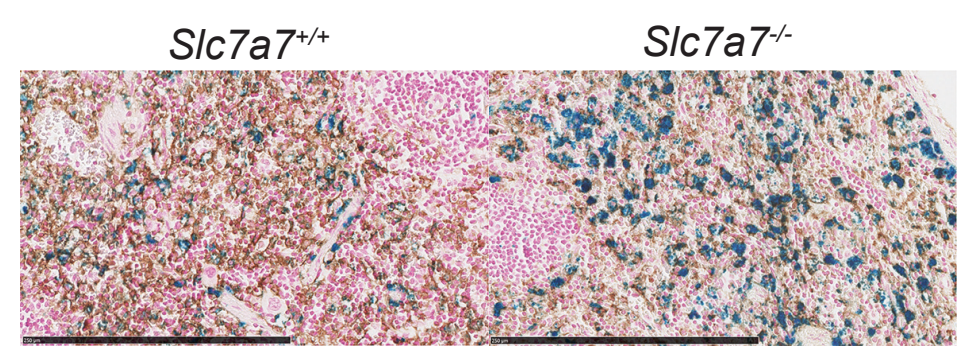




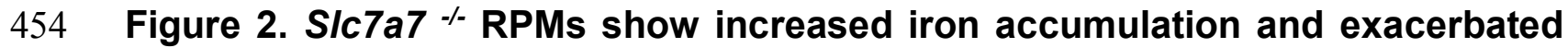

455 iron metabolism. (A) Representative iron Perl's Prussian Blue staining of spleens and

456 bone marrow (BM) from indicated genotype supplemented or not with citrulline $(1 \mathrm{~g} / \mathrm{L}$

457 of drinking water). Scale bars, $500 \mu \mathrm{m}$. (B) Total non-heme iron content from spleen

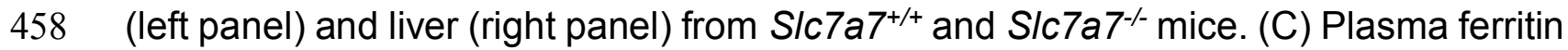

459 quantification of indicated genotype supplemented or not with citrulline. (D) F4/80

460 (brown) and iron (blue) staining of spleen sections of indicated genotype. Scale bar,

$461250 \mu \mathrm{m}$. Data are mean \pm SEM. ${ }^{* *} P \leq 0.01,{ }^{* * *} P \leq 0.001$ between genotypes. ${ }^{\#} P \leq$

$4620.05, \# P \leq 0.01$ vs. S/c7a7-/- mice without citrulline. $P$ and \# values were calculated

463 using two-tailed $t$-test.

464

465

466

467

468

469

470

471

472

473

474

475

476

477 
bioRxiv preprint doi: https://doi.org/10.1101/2021.08.15.456393; this version posted August 16, 2021. The copyright holder for this preprint (which was not certified by peer review) is the author/funder, who has granted bioRxiv a license to display the preprint in perpetuity. It is

A

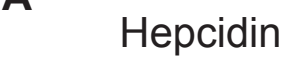

B

Hamp1

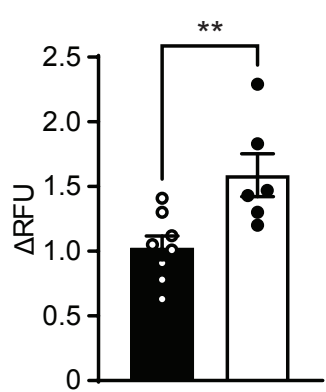

$\operatorname{Sic7a7^{+/+}}$

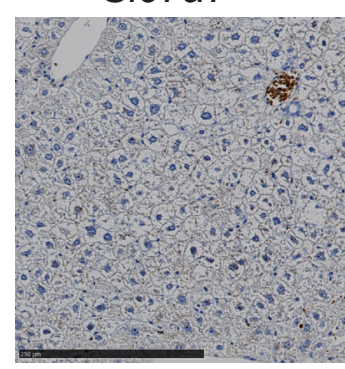

S/c7a7 $\%$

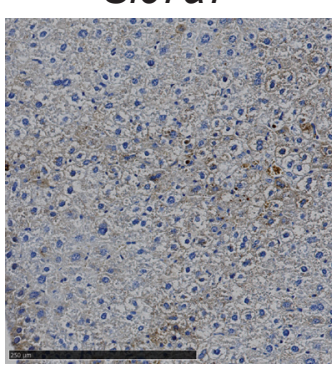

BMP6

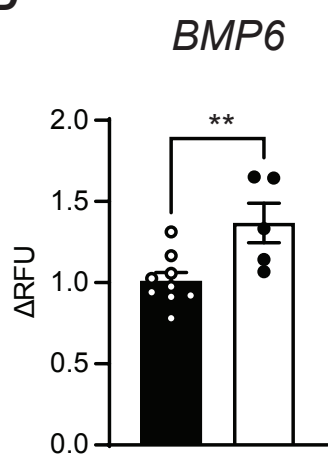

D
E

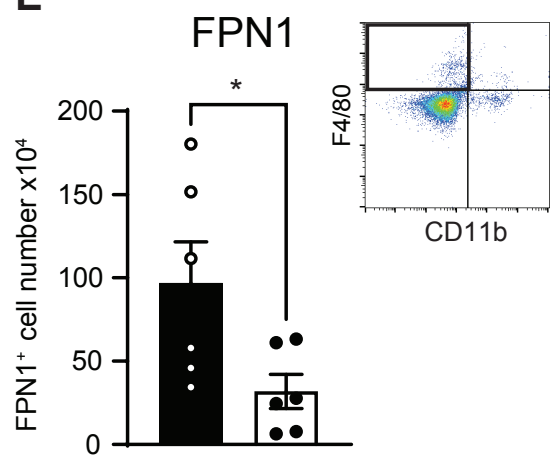

F

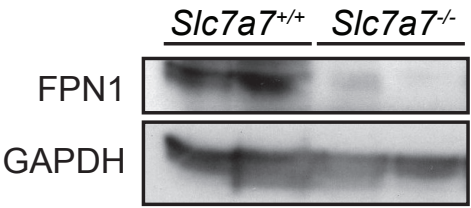

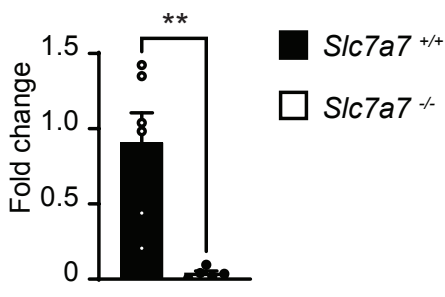


478 Figure 3. Total loss of Slc7a7 results in decreased FPN1 expression. (A) Plasma

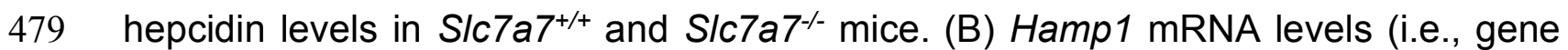

480 encoding for hepcidin) of $S / c 7 a 7^{+/+}$and $S / c 7 a 7^{-/}$mice livers. (C) Iron histology by

481 enhanced Pearl's Prussian blue (brown) staining of liver sections of indicated

482 genotype. Scale bar, $250 \mu \mathrm{m}$. (D) BMP6 mRNA expression of S/c7a7 ${ }^{+/+}$and S/c7a7 $7^{-/-}$

483 mice livers. (E) Absolute cell number of $C D 11 b^{\text {lo }}, F 4 / 80^{\text {hi }}$, FPN1 ${ }^{\text {hi }}$ per spleen and

484 representative FACS plot showing selected gate. (F) FPN1 protein expression in

485 spleen membranes of the indicated genotypes. Quantification is expressed as

486 FPN1/GAPDH fold change. Data are represented as mean \pm SEM. * $P \leq 0.05,{ }^{* *} P \leq$

$487 \quad 0.01$ between genotypes. $P$ values were calculated using two-tailed $t$-test.

488

489

490

491

492

493

494

495

496

497

498

499

500

501 
A $\quad-1.5-1-0.5 \quad 0 \quad 0.5 \quad 1 \quad 1.5$

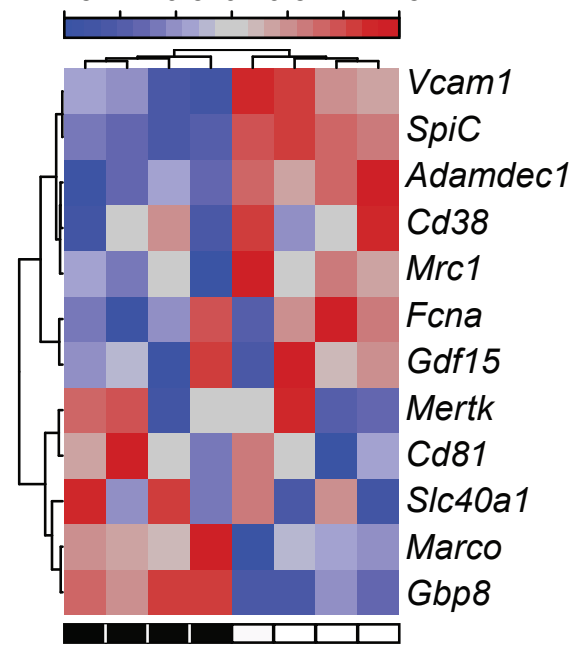

C Bone Marrow Derived Macrophages

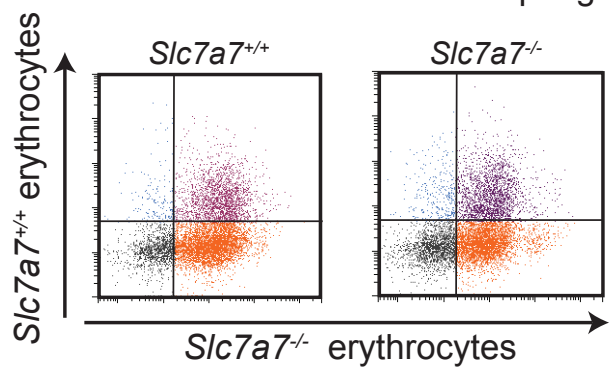

B

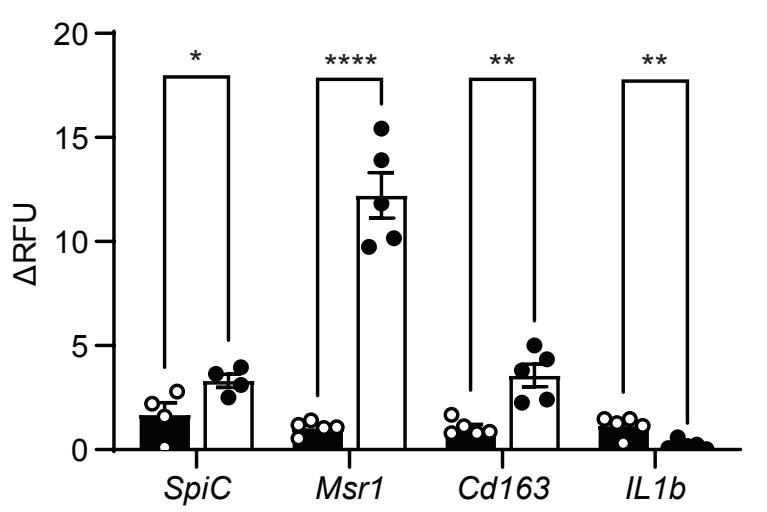

Slc7a7 $7^{+/+}$

$\square S / c 7 a 7^{-1}$

- $S / c 7 a 7^{++}$erythrocytes

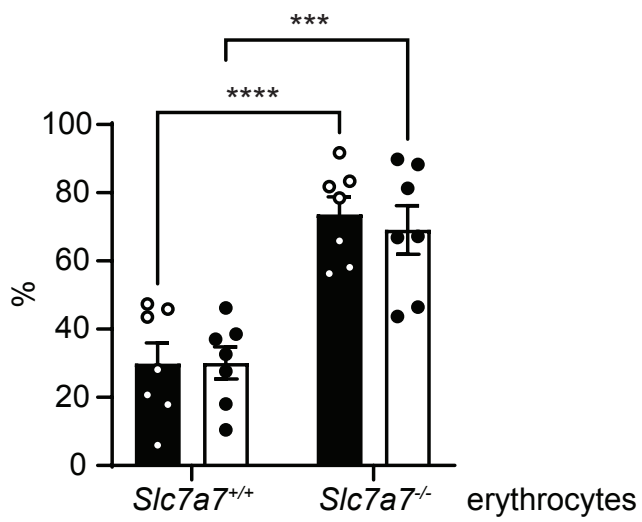

Mixed erythrocytes 
502 Figure 4. $\mathbf{y}^{+}$LAT1 ablation leads to increased erythrophagocytosis. (A) RPMs

$503\left(\mathrm{~F} 4 / 80^{\text {hi }} \mathrm{CD} 11 \mathrm{~b}^{\mathrm{lo}}\right)$ were sorted and gene expression analysis was carried out using the

504 Affymetrix platform and a selection of RPM-associated genes(Haldar et al., 2014;

505 Kohyama et al., 2009) was plotted as a heat map. Black boxes indicate the S/c7a7 $7^{++}$

506 genotype and empty boxes the Slc7a7-/- genotype. (B) Quantitative RT-PCR analysis

507 of mRNA expression levels of indicated genes related to erythrophagocytosis and

508 differentiation in RPM of S/c7a $7^{+/+}$and S/c7a7\% mice. (C) Erythrophagocytosis assay.

509 Briefly, BMDMs were co-incubated with previously labelled erythrocytes. S/c7a7 $7^{++}$

510 erythrocytes (blue circles) were labelled with CellVue Claret, while S/c7a7-/-

511 erythrocytes (orange circles) were labelled with PKH26. Left: Representative dot plots

512 show the gating strategy for the erythrophagocytosis assay. Right: Percentage of the

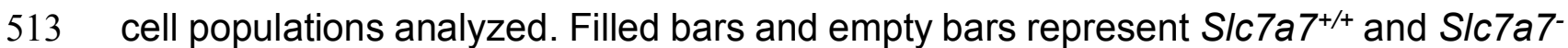

514 /- macrophages, respectively. Data are mean \pm SEM. ${ }^{*} P \leq 0.05,{ }^{* *} P \leq 0.01,{ }^{* * *} P \leq$

$5150.001,{ }^{* * *} P \leq 0.0001$ between genotypes. $P$ values were calculated using two-tailed

$516 \quad t$-test. 
bioRxiv preprint doi: https://doi.org/10.1101/2021.08.15.456393; this version posted August 16, 2021. The copyright holder for this preprint

(which was not certified by peer review) is the author/funder, who has granted bioRxiv a license to display the preprint in perpetuity. It is made available under aCC-BY 4.0 International license.

\section{A Hemoglobin}

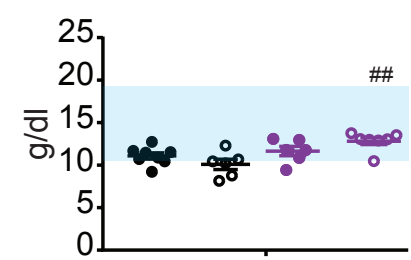

D

MCV

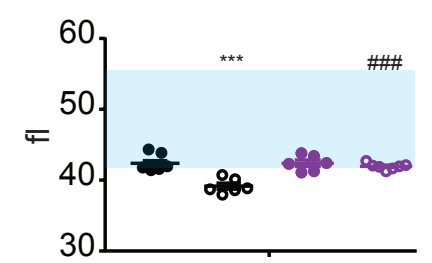

B Hematocrit

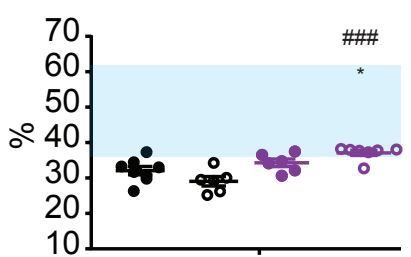

E

$\mathrm{MCH}$

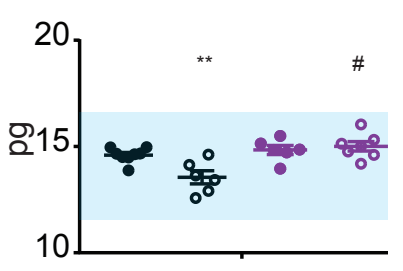

C

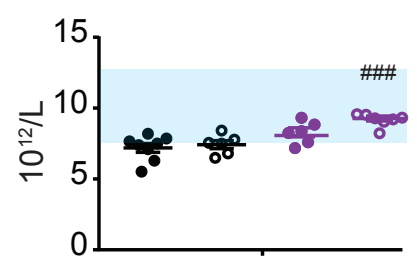

F $\quad$ MPV

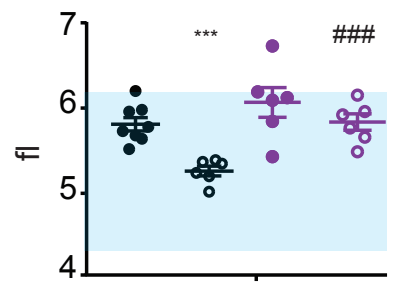

G

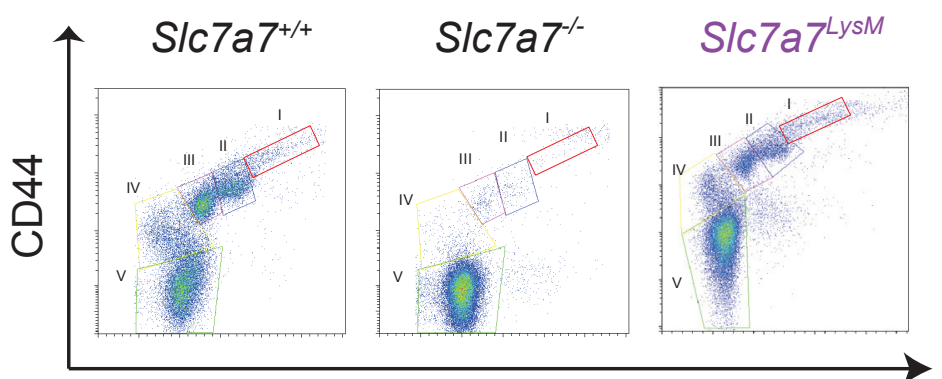

FSC-A

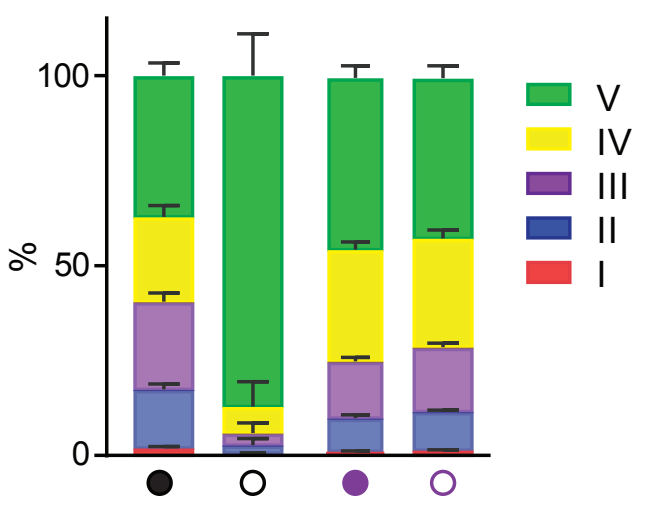

H

Erythropoietin

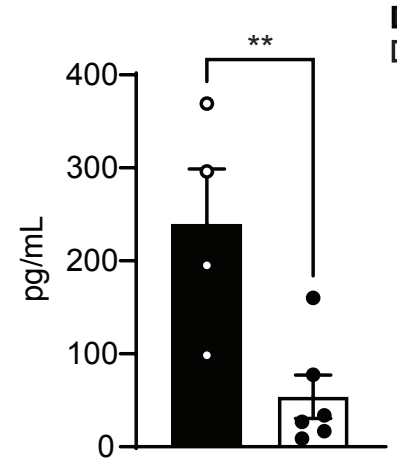

- $S / c 7 a 7^{+/+}$

$\square \operatorname{SIc7a7^{-1}}$ 
526 Figure 5. $\mathbf{y}^{+}$LAT1 depletion results in defective erythropoiesis. (A-F)

527 Quantification of blood hemoglobin (A), hematocrit (B), RBC concentration (C), mean

528 corpuscular volume (D), mean corpuscular hemoglobin (E) and mean platelet volume

529 (F) of indicated genotype. (G) Left: Representative dot plots show the gating strategy

530 for erythroid progenitors (V, IV, III, II and I) (Chen et al., 2009) from indicated genotype.

531 Briefly, cells were first gated in TER $119^{+}$and further separated by CD44 versus

532 Forward Scatter (FSC-A). Right: Percentage of the cell populations analyzed. $(\mathrm{H})$

533 Plasma erythropoietin levels in S/c7a $7^{+/+}$and S/c7a $7^{-/-}$mice fed with a low protein diet.

534 Data are mean \pm SEM. All experiments were performed independently at least twice.

$535{ }^{*} P \leq 0.05,{ }^{* *} P \leq 0.01,{ }^{* *} P \leq 0.001$ between genotypes. $P$ values were calculated

536 using two-tailed $t$-test.

537

538

539

540

541

542

543

544

545

546

547

548

549 
Figure 6. Iron accumulation but not defective hematopoiesis and metabolic prior to sacrifice day. (B-E) Body weight (B), spleen weight (C), plasma arginine (D), and urine orotic acid $(E)$ of S/c7a $7^{--}$mice transplanted with wild-type CD45.2 bone marrow $\left(B M S / c 7 a 7^{+/+} \rightarrow S / c 7 a 7^{-/-}\right)$and $S / c 7 a 7^{+/+}$mice transplanted with SIc7a7 $7^{-/}$ CD45.1 bone marrow (BM Slc7a $\left.7^{-/-} \rightarrow S / c 7 a 7^{+/+}\right)$. (F) Left: Isolated spleens of the indicated genotypes were embedded in paraffin for histopathological examination (Perl's Prussian Blue). Scale bar, $500 \mu \mathrm{m}$. Right: Percentage of iron area in the indicated genotypes and transplanted mice. (G) Plasma ferritin levels in Slc7a7 $7^{+/+}$and

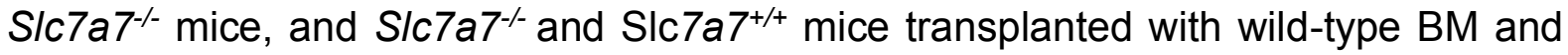
Slc7a7\%- BM, respectively. (H-I) Hematological analysis (MCV, mean corpuscular volume; $\mathrm{MCH}$, mean corpuscular hemoglobin) of S/c7a7-/- mice transplanted with wild-

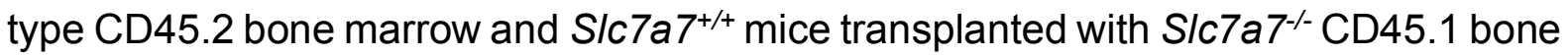
marrow. (J) Left: Representative dot plots show the gating strategy for erythroid progenitors (V, IV, III, II and I) (Chen et al., 2009) of S/c7a $7^{-/-}$mice transplanted with

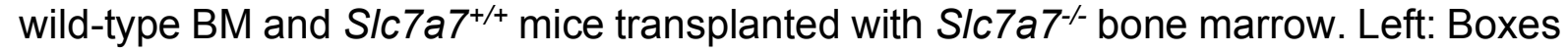
in the flow cytometry plots represents I-IV erythroblasts populations. Right: Percentage of the cell populations analyzed. Data are mean \pm SEM. All experiments were performed independently at least twice. ${ }^{*} P \leq 0.05,{ }^{* *} P \leq 0.01,{ }^{* * *} P \leq 0.001,{ }^{* * *} P \leq$

$570 \quad 0.0001$ between genotypes. $P$ values were calculated using two-tailed $t$-test. 
bioRxiv preprint doi: https://doi.org/10.1101/2021.08.15.456393; this version posted August 16, 2021. The copyright holder for this preprint

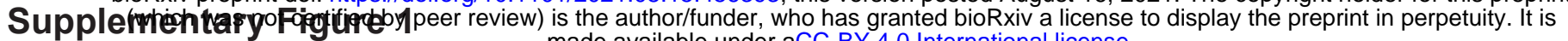

A

Slc7a7 ${ }^{+/+}$SIc7a $7^{-1-}$

ताTाTाTाTाTाTाTाTाT|

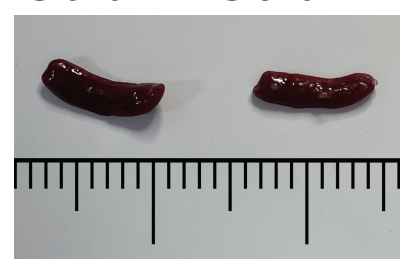

B

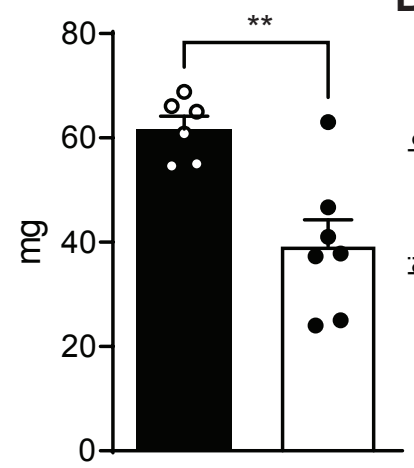

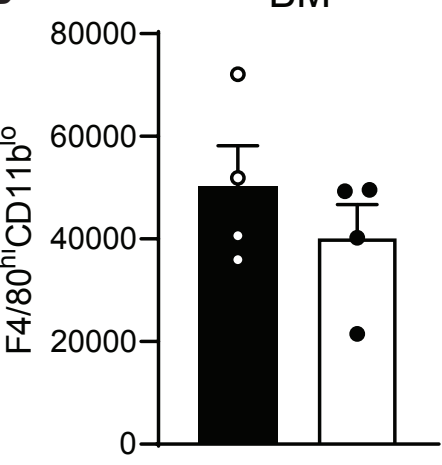

$C_{400000}$ Spleen

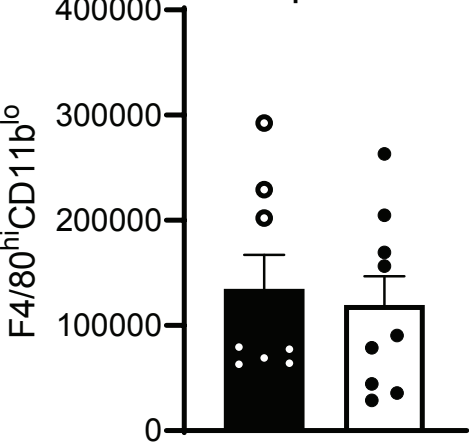

Slc7a7+/+

$\square S / c 7 a 7^{-1}$ 
575 Supplementary Figure 1. Slc7a ${ }^{\text {-/ }}$ mouse model treated with citrulline improve

576 spleen weight and recover BMMs and RPMs number. (A) Slc7a $7^{-/}$mice and its

577 control littermates treated with citrulline in the drinking water $(1 \mathrm{~g} / \mathrm{L})$ were dissected,

578 and spleens were photographed (left panel). Spleen weights are indicated on the right

579 panel. (B) Flow cytometry quantification of total number of bone marrow (BM)

580 macrophages and red pulp macrophages $(C)$ per femur and tibia (CD11 $\left.\mathrm{b}^{\mathrm{lo}}, \mathrm{F} 4 / 80^{\mathrm{hi}}\right)$.

581 Data are mean \pm SEM. ${ }^{* *} P \leq 0.01$ between genotypes. $P$ values were calculated using

582 two-tailed $t$-test.

583

584

585

586

587

588

589

590

591

592

593

594

595

596

597

598 


\section{Supplementary Figure 2}

A

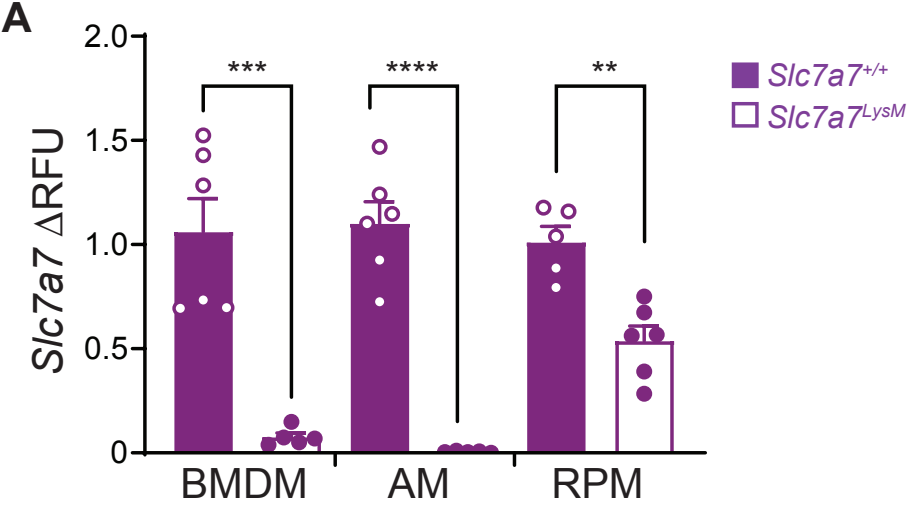

B

C
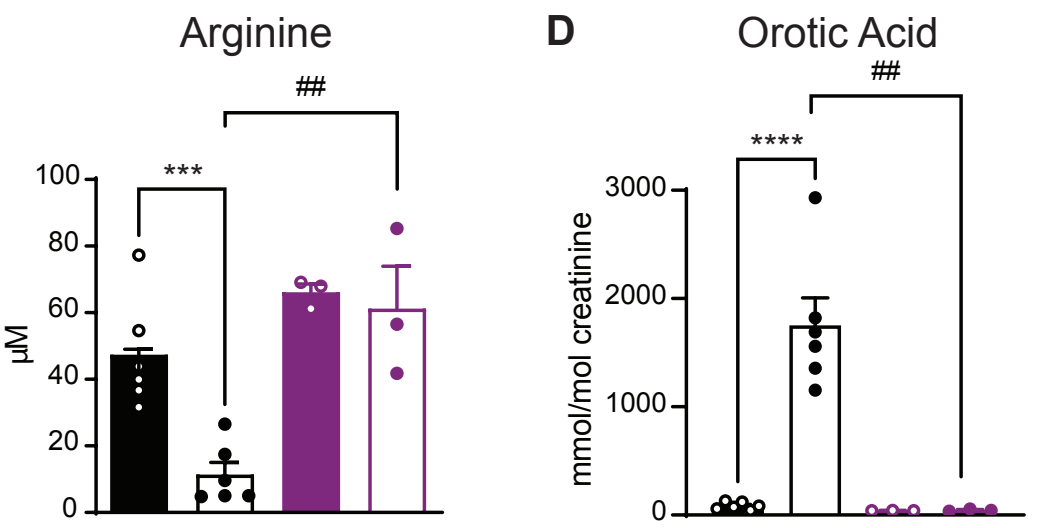

E Spleen

F Body weight

$40 \mathrm{KDa}$
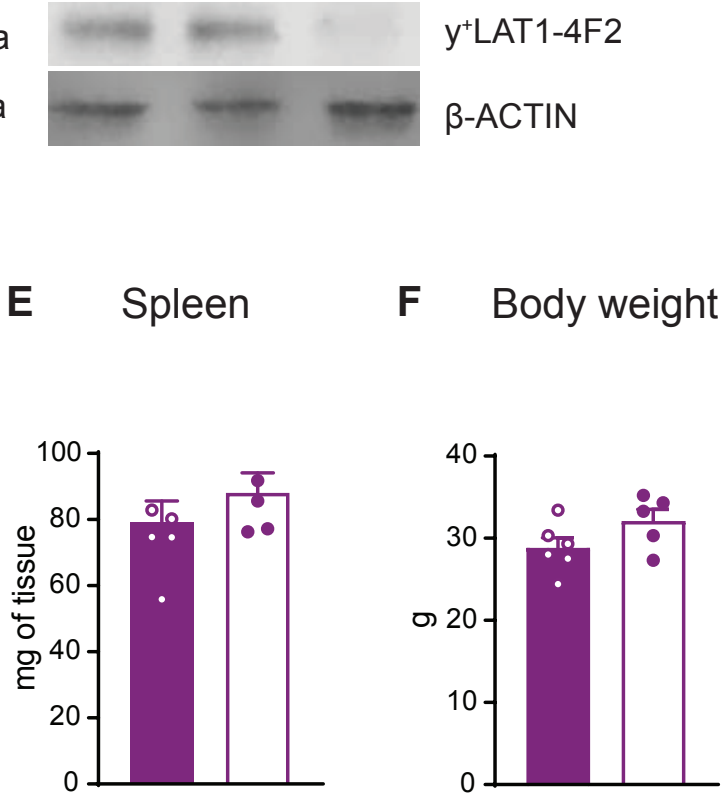

G
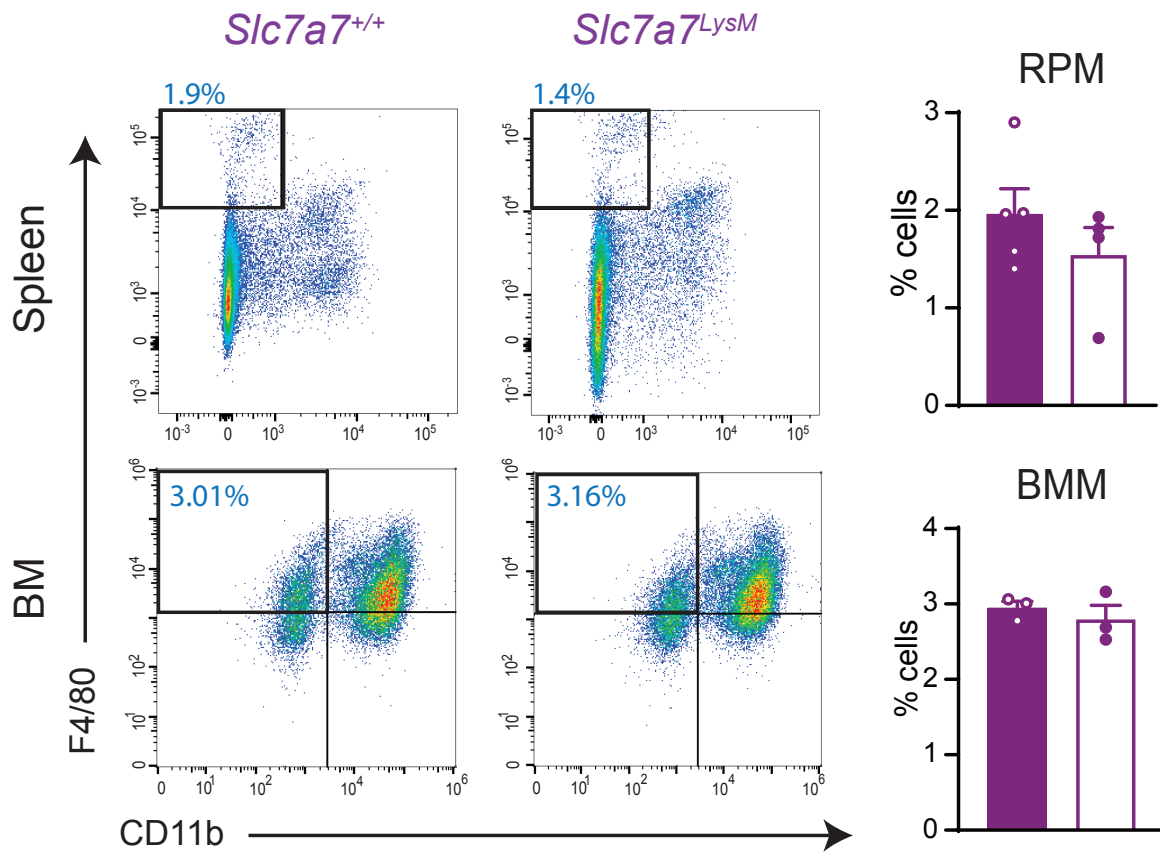

BMM

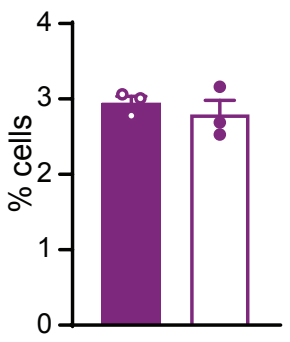


599 Supplementary Figure 2. $\mathbf{y}^{+}$LAT1 deficiency in myeloid cell line does not

600 reproduce the deficiencies of the conditional knockout mouse. (A) mRNA

601 expression of Slc7a7 gene in BMDMs, AMs and RPMs from Slc7a74ysM-/- and their

602 control. (B) $\mathrm{y}^{+} \mathrm{LAT1}$ protein expression of kidney membranes in the indicated

603 genotypes. (C) Plasma arginine, (D) urine orotic acid, (E) spleen and (F) body weight

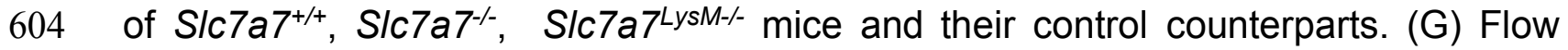
605 cytometry analysis with the indicated markers on BMs and splenocytes of the

606 designated genotypes. The percentage of CD11blof $4 / 80^{\text {hi }}$ is shown (right panel). Data 607 are mean \pm SEM. ${ }^{* *} P \leq 0.01,{ }^{* * *} P \leq 0.001$ between genotypes. ${ }^{\#} P \leq 0.05,{ }^{\#} P \leq 0.01$ 608 vs. S/c7a $7^{-/}$mice. $P$ values were calculated using two-tailed $t$-test.

609

610

611

612

613

614

615

616

617

618

619

620

621

622

623 
Sunn bioRxiy preprint doi: https;//doi.org/10.1101/2021.08.15.456393; this version posted August 16, 2021. The copyright holder for this preprint Supplem(andards hdigliffed 3 y peer review) is the author/funder, who has granted bioRxiv a license to display the preprint in perpetuity. It is A

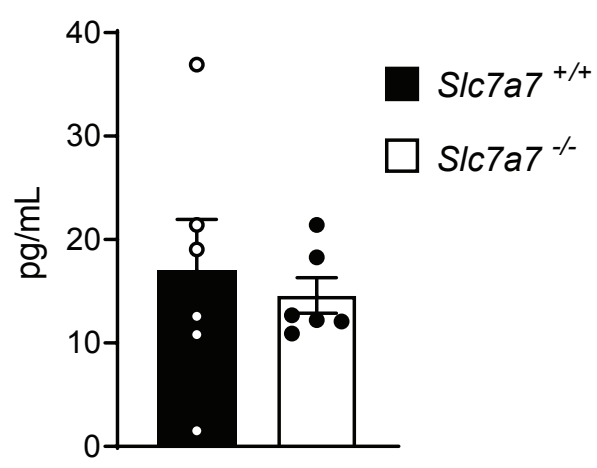

B

\begin{tabular}{|l|l|l|}
\hline Hallmark Term & PValue & NES \\
\hline UV response DN & 0.001 & 2.584 \\
\hline Xenobiotic metabolism & 0.044 & 2.025 \\
\hline Complement & 0.026 & 1.883 \\
\hline Wnt- $\beta$ catenin signaling & 0.012 & 1.855 \\
\hline Protein secretion & 0.043 & 1.624 \\
\hline G2M checkpoint & 0 & -3.917 \\
\hline IL2 STAT5 signaling & 0 & -3.311 \\
\hline Mitotic spindle & 0 & -3.07 \\
\hline Inflammatory response & 0 & -3.049 \\
\hline IL6 JAK STAT3 signaling & 0 & -2.797 \\
\hline TNF- $\alpha$ signaling via NFKB & 0.001 & -2.599 \\
\hline Interferon response & 0.001 & -2.584 \\
\hline Allograft rejection & 0 & -2.569 \\
\hline Estrogen response late & 0.007 & -2.518 \\
\hline KRAS signaling up & 0.007 & -2.509 \\
\hline E2F Targets & 0 & -2.469 \\
\hline Angiogenesis & 0.005 & -2.263 \\
\hline Apoptosis & 0 & -2.132 \\
\hline Apical Junction & 0.009 & -2.13 \\
\hline Unfolded protein response & 0.009 & -2.099 \\
\hline Estrogen response early & 0.017 & -1.981 \\
\hline Glycolysis & 0.054 & -1.975 \\
\hline mTORC1 SIGNALING & 0.033 & -1.913 \\
\hline P53 Pathway & 0.094 & -1.637 \\
\hline Fatty acid metabolism & 0.131 & -1.557 \\
\hline Heme metabolism & 0.187 & -1.412 \\
\hline
\end{tabular}


624 Supplementary Figure 3. IL6 plasma levels and broad hallmarks patways

625 (A) Plasma IL6 levels of $S / c 7 a 7^{+/+}$and S/c7a $7^{-/-}$mice. Data are mean \pm SEM. $P$ values

626 were calculated using two-tailed $t$-test. (B) The most significative pathways in Slc7a7-

627 / red pulp macrophages, Pvalue and Normalized Enrichment Score (NES) values are

628 shown.

629

630

631

632

633

634

635

636

637

638

639

640

641

642

643

644

645

646

647

648 
MATERIALS AND METHODS

\section{Data and code availability}

651 Microarray data has been deposited in a public repository and the accession

652 numbers is GSE164827.

\section{Animals}

654 All animal work was approved and conducted according to guidelines established. This project (DARP $\mathrm{n}^{\circ} 9177$ ) has been assessed favourably by the Institutional Animal Care and Use Committee from Parc Científic de Barcelona (IACUC-PCB) and the IACUC considers that the above-mentioned project complies with standard ethical regulations and meets the requirements of current applicable legislation (RD 53/2013 Council

659 Directive; 2010/63/UE; Order 214/1997/GC). C57BL/6 mice were purchased from

660 Harlan Europe. S/c7a7loxp/loxp mice were generated by Eurogentec. To generate

661 S/c7a7 $7^{-/}$and S/c7a $7^{L y s M}$ mice, S/c7a $7^{\text {loxp/loxp }}$ were crossed with UBC-Cre-ERT2 mice

662 from The Jackson Laboratory and LysM-Cre provided by Dr. Ángel R. Nebreda, 663 respectively. Male or female mice of 12 weeks old were used. Mice were housed in 664 groups of 2-5 animals per cage and were kept under a $12 \mathrm{~h}$ dark-light period. Food and water were supplied ad libitum. Animals were fed a standard diet (Teklad global $14 \%$ protein rodent maintenance diet) until tamoxifen induction, which consisted of a

667 tamoxifen diet for one week. After the induction period, animals were kept on a low668 protein diet for 7-10 days, supplemented or not with $1 \mathrm{~g} / \mathrm{L}$-citrulline in drinking water.

669 Control and S/c7a $7^{-/}$littermates on a C57B|6/J genetic background were sacrificed at 670 10-12 weeks of age by cervical dislocation. Tissues were dissected and flash-frozen 671 in liquid nitrogen for RNA, protein, and iron quantification studies. For histological 672 analysis, mice were anesthetized with ketamine and xylazin (respectively $1 \mathrm{mg}$ and $6730.1 \mathrm{mg}$ per $10 \mathrm{~g}$ of body weight, i.p., respectively) and subjected to transcranial 
perfusion. For hematological and biochemical studies, EDTA or heparin blood was collected from cardiac puncture. Bone marrow was flushed out from femur and tibia bones.

677 Mice carrying the myeloid-specific knockout of the Slc7a7 gene (LysMcre/+ 678 Slc7a $7^{\text {floxflox }}$ ) were sacrificed at 12 weeks of age, and only those with more than $80 \%$ 679 deletion of endogenous protein were used for the experiments.

\section{Bone marrow transplantation (BMT)}

681 Recipient mice were lethally irradiated (9.5Gy) and transplanted with $2 \times 10^{6}$ bone 682 marrow (BM) cells by retro-orbital injection (Bennett et al., 2018). For the re-population

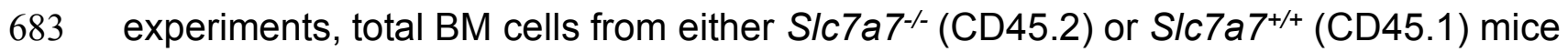
684 were transplanted into lethally irradiated B6 recipient mice (CD45.1 or CD45.2). As a 685 follow-up step, five weeks after transplantation to allow whole body hematopoiesis regeneration, mice were subjected to tamoxifen diet for 7 days, and then treated with a low-protein diet for 10 days prior to the sacrifice. BM reconstitution was monitored by flow cytometry.

$689 \mathrm{Y}$-Irradiation of mice was performed in a 137Cs-y IBL 437C H irradiator (Shering CIS bio international) at $2.56 \mathrm{~Gy} / \mathrm{min}$ rate for the indicated dosage. The irradiated mice were

691 inspected daily. Mice were given Baytril water containing antibiotics (Bayer, Shawnee 692 Mission, JS) for at least 30 days to reduce the probability of infection from opportunistic 693 pathogens.

\section{Flow cytometry and cell sorting}

695 For the analysis of splenocytes and bone marrow cells, crushed spleens and flushed 696 BM were isolated and incubated with Fc block (anti-mouse CD16/32; Thermofisher) 697 for 30 min on ice. Cell suspensions were stained for the expression of CD71; CD11b; 698 CD45.1; CD45.2 (BD Biosciences); CD34 (eBiosciences); F4/80; TER119; CD106 
699 (BioLegend) for 30 min on ice. Flow cytometry analysis was performed on Gallios (BD

700 Boisciences). For spleen staining, crushed tissues were filtered through a $40 \mu \mathrm{M}$ cell

701 strainer and erythroid cells were removed by incubation with ammonium-chloride-

702 potassium lysis buffer prior to Fc blocking. Cell sorting (purity $>90 \%$ ) was carried out

703 using a FACS Aria II (BD Biosciences). For microarray analysis, spleens were

704 prepared as described above and stained with anti-CD106, anti-CD11b and anti-F4/80

705 (ThermoFisher) for purified RPMs.

706 Cell doublets were excluded from all analyses and, when possible, dead cells were

707 excluded by the use of DAPI. Data analysis was carried out using FlowJo ${ }^{\text {TM }}$ Software.

\section{In vitro erythrophagocytosis assay}

709 To prepare primary BMDMs, cells obtained from mouse femurs and tibia were cultured

710 for 7 days in the presence of L-Cell (L929 SN) in DMEM supplemented with 10\% FBS,

711 penicillin $(50 \mathrm{U} / \mathrm{mL})$ and streptomycin $(50 \mu \mathrm{g} / \mathrm{mL})$. BMDMs were plated 24 hours prior

712 to the day of the experiment. On the day of the experiment, previously seeded BMDMs

713 were activated with lipopolysaccharide $(100 \mathrm{ng} / \mathrm{mL})$ for $2 \mathrm{~h}$ and fresh RBCs were extracted, washed and labelled with CellVue ${ }^{\circledR}$ or PKH26 following the manufacturer's

715 instructions. RBCs were then incubated with previously activated BMDMs for 2 716 minutes $\left(10 \cdot 10^{6} \mathrm{RBC} / 1 \cdot 10^{6} \mathrm{BMDM}\right)$ at $37^{\circ} \mathrm{C}$ in a $5 \% \mathrm{CO}_{2}$ incubator. Macrophages 717 were washed twice with PBS and finally incubated with an erythrolysis buffer (R\&D

718 Systems) to lyse non-ingested RBCs. Cells were then collected and analyzed by flow 719 cytometry.

\section{Histological sample preparation and analysis}

721 Samples were fixed overnight at $4^{\circ} \mathrm{C}$ with neutral buffered formalin. After fixation, 722 bone tissue (femur) was washed with PBS 1x and decalcified with Osteosoft ${ }^{\circledR}$ reagent 
723 for a minimum 15 days at RT. All samples were embedded in paraffin. Paraffin-

724 embedded tissue sections (2-3 $\mu \mathrm{m}$ in thickness) were air-dried and further dried at 60

$725{ }^{\circ} \mathrm{C}$ overnight. Bone sections were maintained at $60^{\circ} \mathrm{C}$ for $48 \mathrm{~h}$.

726 For special staining, paraffin-embedded tissue sections were dewaxed and stained

727 with Iron Stain Kit to identify iron pigment using the Dako Autostainer Plus and

728 following the manufacturer instructions. When combining Iron staining with $\mathrm{F} 4 / 80 \mathrm{IHC}$,

729 iron staining was done before following the described protocols.

730 Prior to immunohistochemistry, sections were dewaxed and therefore epitope retrieval 731 was performed using citrate buffer $\mathrm{pH} 6$ for 20 min at $121^{\circ} \mathrm{C}$ with an autoclave or

732 proteinase $\mathrm{K}$ for $5 \mathrm{~min}$ at RT for anti-caspase 3 (Cell Signalling) and rat monoclonal 733 Anti-F4/80 (eBioscience), respectively. For rabbit polyclonal anti-Ki67 (Abcam) 734 sections were dewaxed as part of the antigen retrieval process using the low $\mathrm{pH}$ 735 EnVision $^{\mathrm{TM}}$ FLEX Target Retrieval Solutions (Dako, Burlington) for $20 \mathrm{~min}$ at $97^{\circ} \mathrm{C}$ 736 using a PT Link (Dako, Agilent). Quenching of endogenous peroxidase was performed 737 by 10 min of incubation with Peroxidase-Blocking Solution at RT. Non-specific 738 bindings were blocked using $5 \%$ of goat normal serum or normal donkey serum mixed with $2.5 \%$ BSA diluted in the wash buffer for 60 min at RT. The primary antibody

740 dilutions used were $1: 300,1: 100$ and $1: 2000$, for $120 \mathrm{~min}$, overnight or $60 \mathrm{~min}$, 741 respectively. The secondary antibody used was a BrightVision Poly-HRP-Anti Rabbit 742 IgG Biotin-free, ready to use or the secondary antibody used was a Biotin-SP (long 743 spacer) AffiniPure Donkey Anti-Rat $\lg \mathrm{G}(\mathrm{H}+\mathrm{L})$ at 1:500 (in wash buffer) for 60 min followed by amplification with Streptavidin-Peroxidase polymer at 1:1000. Antigenantibody complexes were revealed with 3-3'-diaminobenzidine, with the same time exposure $(1 \mathrm{~min})$. Sections were counterstained with hematoxylin and mounted with 
747

748

749

750

751

752

753

754

755

756

757

758

759

760

761

762

763

764

765

766

767

768

769

770

771

Mounting Medium, Toluene-Free using a Dako CoverStainer. Specificity of staining was confirmed with rabbit IgG, polyclonal - Isotype control or Normal Rat IgG Control. Image acquisition. Brightfield images were acquired with a NanoZoomer-2.0 HT C9600 digital scanner (Hamamatsu) equipped with a 20X objective. All images were visualized with the NDP.view 2 U123888-01 software. All images were visualized with a gamma correction set at 1.8 in the image control panel of the NDP.view 2 U1238801 software.

Prior to immunohistochemistry, for Ki67 sections were dewaxed as part of the antigen retrieval process using the low pH EnVision ${ }^{\mathrm{TM}}$ FLEX Target Retrieval Solutions (Dako, Burlington) for $20 \mathrm{~min}$ at $97^{\circ} \mathrm{C}$ using a PT Link (Dako - Agilent). For caspase 3 samples were dewaxed and antigen retrieval treatment was performed with citrate buffer $\mathrm{pH} 6$ for $20 \mathrm{~min}$ at $121^{\circ} \mathrm{C}$ with an autoclave. Quenching of endogenous peroxidase was performed by 10 min of incubation with Peroxidase-Blocking Solution (Dako REAL S2023). Rabbit polyclonal primary anti-Ki67 antibody (A. Menarini diagnostics - NCLki67p) was diluted 1:1000 with EnVision FLEX Antibody Diluent (K800621, Dako, Agilent) and incubated for $60 \mathrm{~min}$ at RT. The secondary antibody used was a BrightVision Poly-HRP-Anti Rabbit IgG Biotin-free, ready to use (Immunologic, DPVR110HRP). Antigen-antibody complexes were revealed with 3-3'-diaminobenzidine, with the same time exposure per antibody ( 3 and 5 min respectively). Sections were counterstained with hematoxylin and mounted with Mounting Medium, Toluene-Free using a Dako CoverStainer.

\section{Amino acid content}

Briefly, amino acids were determined by ion exchange chromatography with ninhydrin derivatization and spectrometric detection (Biochrom 30, Chromsystems, Cambridge, UK). Plasma $(300 \mu \mathrm{L})$ were deproteinized with sulphosalicylic acid containing L- 
772

773

774

775

776

777

778

779

780

781

782

783

784

785

786

787

788

789

790

791

792

793

794

795

norleucine as internal standard (final concentration $100 \mu \mathrm{mol} / \mathrm{L}$ ). After centrifugation, $200 \mu \mathrm{L}$ of supernatant were adjusted to $\mathrm{pH}=2.1$ with lithium hydroxide, and then, injected onto the liquid chromatograph. Urinary orotic acid was analyzed following a spectrometric procedure $(458 \mathrm{~nm})$, by reacting with paradimethylaminobenzaldehyde.

\section{Tissue iron content}

Liver and spleen non-heme iron content was measured using the bathophenanthroline colorimetric method. Mouse tissues were dried at $45^{\circ} \mathrm{C}$ for 3 days, weighted, and digested for $48 \mathrm{~h}$ at $65^{\circ} \mathrm{C}$ in $10 \% \mathrm{TCA} / 10 \% \mathrm{HCl}$ to allow deproteinization of non-heme iron. Diluted extracts were added to a $0.01 \%$ bathophenanthroline disulfonic acid, $0.1 \%$ thioglycolic, $7 \mathrm{M}$ sodium acetate solution and the absorbance at $535 \mathrm{~nm}$ was measured using a spectrophotometer Ultrospec 3100pro (Amersham Biosciences). The iron content of samples was obtained by interpolation from a standard curve and calibrated to the weight of dried material (Jd and Th, 1968; Patel et al., 2002).

\section{Plasma measurements}

ELISA kit was used to determine the IL6 (Abnova), hepcidin (Intrinsic Life Science), ferritin (Abcam) and erythropoietin (R\&D Systems) proteins in fresh plasma. The procedures were done following the manufacturer's instructions.

\section{Microarray analysis}

For gene expression analysis of RPMs, total RNA was isolated from previously purified cells using magnetic beads and the Agencourt RNA Clean XP kit (Beckman Coulter). Quality and quantity were assessed using a Bioanalyzer 2100 (Agilent Technologies, Palo Alto, CA). Library preparation and amplification were performed as described previously by (Gonzalez-Roca et al., 2010). RNA was amplified for 22 cycles and 
purified using PureLink Quick PCR Purification kit (Invitrogen) in the Genomic Facility of IRB Barcelona.

\section{Pre-processing of microarray data}

Microarray datasets were processed separately using $R$ (R Core, 2019) packages affy

800 (Gautier et al., 2004) and affyPLM (Bolstad et al., 2005) from Bioconductor

801 (Gentleman et al., 2004). Raw cell files data were processed using RMA (Irizarry,

802 2003) and annotated using the information available on the Affymetrix - Thermofisher web page. Standard quality controls were performed in order to identify abnormal pseudo-images from probe level models); b) intensity dependences of differences between chips (MvA plots); c) RNA quality (RNA digest plot); d) global intensity levels

807 (boxplot of perfect match log-intensity distributions before and after normalization and 808 RLE plots); and e) anomalous intensity profile compared to the rest of the samples 809 (NUSE plots, Principal Component Analysis).

\section{Differential expression}

811 A differential expression analysis was performed for $S / c 7 a 7^{+/+}$and $S / c 7 a 7^{-/-}$

812 comparisons using a linear model with empirical shrinkage (Smyth, 2004) as

813 implemented in Limma R package (Ritchie et al., 2015). This model included the batch 814 of scanning for statistical control. Adjustment by multiple comparisons was performed 815 using the Benjamini-Hochberg method (Benjamini and Hochberg, 1995).

\section{Biological enrichment analysis}

817 Genes quantified in the microarray experiment were annotated according to the Broad 818 Hallmark (Liberzon et al., 2015) gene sets collection. Broad Hallmark sets were 
819 translated to mouse homologous genes using the R package biomaRt (Durinck et al.,

820 2009).

821 Functional enrichment analyses were performed using a modification of ROAST (Wu

822 et al., 2010), a rotation-based approach implemented in the R package limma (Ritchie

823 et al., 2015) that is especially suitable for small size experiments. Such modifications 824 were implemented to accommodate in the ROAST algorithm the statistical re825 standardization proposed in (Efron and Tibshirani, 2007), which enables its use for 826 competitive testing (Goeman and Bühlmann, 2007). The MaxMean (Efron and

827 Tibshirani, 2007) statistic was used for testing geneset enrichment of Broad Hallmark.

828 For each gene, the most variable probeset within each gene was used in these analyses (median absolute deviation).

830 The results of these analyses were adjusted by multiple comparisons using the

831 Benjamini-Hochberg False Discovery Rate method (Benjamini and Hochberg, 1995).

\section{Clustering and visualization}

833 Gene expression of selected genes was graphically represented in a heatmap with the 834 heatmap $\mathrm{R}$ package, using a blue to red gradation, where red indicated the highest expression and blue corresponded to the lowest expression values. Previously, the expression data were summarized to the gene level using the most variable probeset

837 mapping to the same gene (median absolute deviation), and expression values were

838 centered and scaled gene-wise. Genes and samples were clustered using the Ward 839 agglomeration method and the correlation and Euclidean distances, respectively. To

840 gain clarity in the graphic, the most extreme values were truncated to -1.5 and 1.5 .

841 All analyses were carried out using $\mathrm{R}$ and Bioconductor.

842 RNA extraction and quantitative real-time PCR 
Mice were killed by cervical dislocation, and tissues were immediately frozen for RNA

844 isolation. Total mRNA was extracted from BMDMs or AMs using the Rneasy Total

845 RNA Isolation kit (Qiagen, Alameda, CA, USA), following the manufacturer's

846 instructions. RNA concentrations were measured with Nanodrop ND-1000

847 (ThermoFisher Scientific). Reverse transcription was performed with total RNA (2 ng)

848 using the qScript cDNA SuperMix (Quantabio) following the manufacturer's

849 instructions. PCRs were performed using the ABI Prism 7900 HT real-time PCR

850 machine (Applied Biosystems, USA) and the SYBR® Green PCR Master Mix. Gene

851 expression levels were normalized with $\beta$-actin as housekeeping genes. Primers used

852 are listed in Supplementary table 1.

853 Protein isolation and western blot

854 Membrane proteins from cell cultures or tissues were extracted with Lysis buffer (25

$855 \mathrm{mM}$ Hepes, 4 mM EDTA, 250 mM Sucrose) containing protease inhibitor (1:000;

856 Protease Inhibitor Cocktail Set III, EDTA-Free, Calbiochem). Briefly, tissues were

857 lysed using the Tissue Lyser (Mini-beadbeater-16, Biospecproducts) and further

858 centrifuged at $10000 \mathrm{~g}$ for 10 minutes at $4^{\circ} \mathrm{C}$. After centrifuging, the supernatant was

859 centrifuged again on an ultracentrifuge at $55000 \mathrm{rpm}$ for 1 hour at $4^{\circ} \mathrm{C}$. Finally, protein

860 concentration was determined using Pierce BCA Protein Assay Kit (ThermoFisher

861 Scientific). Membrane proteins were resolved in 10\% acrylamide gels for SDS-PAGE

862 and transferred to Immobilon membranes (Millipore). The following antibodies were

863 used: polyclonal rabbit anti-y ${ }^{+}$LAT1 was used at 1:750 dilution with $5 \%$ non-fat dried

864 milk in PBS Tween-20 (0.1\%) (Bodoy et al., 2019); rabbit anti-FPN1 was used at 1:250

865 dilution with 5\% non-fat dried milk in TBS Tween-20 (0.1\%) (Nairz et al., 2013).

866 Antibody binding was then detected using appropriate horseradish peroxidase (HRP)- 
conjugated secondary antibodies (1:1000 dilution). Proteins were detected by the

by scanning densitometry.

Primary bone marrow macrophages (BMDMs) cell culture

BM cells from 12-week-old mice (either female or male) were flushed from mice femurs and tibias. The cell suspension was lysed for 5 min in ACK lysis buffer at RT and then washed, resuspended, and cultured for 7 days in Dulbecco's Modified Eagle Medium (DMEM) supplemented with $10 \%$ heat-inactivated fetal bovine serum (FBS), $50 \mathrm{U} / \mathrm{mL}$

harvested and re-seeded with the specific conditioned media for 24 hours. To deplete arginine, arginine-free media was used (DMEM for SILAC, ThermoFisher).

\section{QUANTIFICATION AND STATISTICAL ANALYSIS}

880 Data were analyzed using GraphPad Prism Version 8 software. Statistical analysis in each figure legend.

\section{References}

A-Gonzalez N, Quintana JA, García-Silva S, Mazariegos M, de la Aleja AG, Nicolás-ávila JA, Walter W, Adrover JM, Crainiciuc G, Kuchroo VK, Rothlin C V., Peinado H, Castrillo A, Ricote M, Hidalgo A. 2017. Phagocytosis imprints heterogeneity in tissue-resident macrophages. J Exp Med 214:1281-1296. doi:10.1084/jem.20161375

Al-Qattan S, Malcolmson C, Mercimek-Andrews S. 2021. Lysinuric protein intolerance mimicking $\mathrm{N}$-acetylglutamate synthase deficiency in a nine-year-old boy. Mol Genet Metab Reports 27:100741. doi:10.1016/j.ymgmr.2021.100741

Alqarajeh F, Omorodion J, Bosfield K, Shur N, Ferreira CR. 2020. Lysinuric protein intolerance: Pearls to detect this otherwise easily missed diagnosis. Transl Sci Rare Dis 5:81-86. doi:10.3233/TRD-190035

Andriopoulos B, Corradini E, Xia Y, Faasse SA, Chen S, Grgurevic L, Knutson MD, Pietrangelo A, Vukicevic S, Lin HY, Babitt JL. 2009. BMP6 is a key endogenous regulator of hepcidin expression and iron metabolism. Nat Genet 41:482-487. doi:10.1038/ng.335 
903

904

905

906

907

908

909

910

911

912

913

914

915

916

917

918

919

920

921

922

923

924

925

926

927

928

929

930

931

932

933

934

935

936

937

938

939

940

941

942

943

944

945

946

947

948

949

950

951

952

953
Barilli A, Rotoli BM, Visigalli R, Bussolati O, Gazzola GC, Gatti R, Dionisi-Vici C, Martinelli D, Goffredo BM, Font-Llitjós M, Mariani F, Luisetti M, Dall'Asta V. 2012. Impaired phagocytosis in macrophages from patients affected by lysinuric protein intolerance. Mol Genet Metab 105:585-589. doi:10.1016/j.ymgme.2012.01.008

Beaumont C, Delaby C. 2009. Recycling Iron in Normal and Pathological States. Semin Hematol 46:328-338. doi:10.1053/j.seminhematol.2009.06.004

Beguin Y. 1998. Prediction of response to optimize outcome of treatment with erythropoietin. Semin Oncol 25:27-34.

Benjamini Y, Hochberg Y. 1995. Controlling the False Discovery Rate: A Practical and Powerful Approach to Multiple Testing. J R Stat Soc Ser B 57:289-300. doi:10.1111/j.2517-6161.1995.tb02031.x

Bennett LF, Liao C, Paulson RF. 2018. Stress erythropoiesis model systemsMethods in Molecular Biology. Humana Press Inc. pp. 91-102. doi:10.1007/978-1-4939-7428-3_5

Bodoy, Sotillo, Espino-Guarch, Sperandeo, Ormazabal, Zorzano, Sebastio, Artuch, Palacín, Bodoy S, Sotillo F, Espino-Guarch M, Sperandeo MP, Ormazabal A, Zorzano A, Sebastio G, Artuch R, Palacín M. 2019. Inducible Slc7a7 Knockout Mouse Model Recapitulates Lysinuric Protein Intolerance Disease. Int J Mol Sci 20:5294. doi:10.3390/ijms20215294

Bolstad B, Collin F, Brettschneider J, Simpson K, Cope L, Irizarry R, Speet T. 2005. Quality Assessment of Affymetrix GeneChip Data In: Gentleman R, Carey V, Huber W, Irizarry $\mathrm{R}$, Dudoit S, editors. Bioinformatics and Computational Biology Solutions Using R and Bioconductor. New York, NY: Springer-Verlag. pp. 33-47. doi:10.1007/0-387-293620_3

Bronte $\mathrm{V}$, Zanovello P. 2005. Regulation of immune responses by L-arginine metabolism. Nat Rev Immunol. doi:10.1038/nri1668

Chen K, Liu J, Heck S, Chasis JA, An X, Mohandas N. 2009. Resolving the distinct stages in erythroid differentiation based on dynamic changes in membrane protein expression during erythropoiesis. Proc Natl Acad Sci 106:17413-17418. doi:10.1073/pnas.0909296106

Chow A, Huggins M, Ahmed J, Hashimoto D, Lucas D, Kunisaki Y, Pinho S, Leboeuf M, Noizat C, Van Rooijen N, Tanaka M, Zhao ZJ, Bergman A, Merad M, Frenette PS. 2013. CD169 + macrophages provide a niche promoting erythropoiesis under homeostasis and stress. Nat Med 19:429-436. doi:10.1038/nm.3057

Cobbold SA, Llinás M, Kirk K. 2016. Sequestration and metabolism of host cell arginine by the intraerythrocytic malaria parasite Plasmodium falciparum. Cell Microbiol 18:820830. doi:10.1111/cmi.12552

Cohen LA, Gutierrez L, Weiss A, Leichtmann-Bardoogo Y, Zhang DL, Crooks DR, Sougrat R, Morgenstern A, Galy B, Hentze MW, Lazaro FJ, Rouault TA, Meyron-Holtz EG. 2010. Serum ferritin is derived primarily from macrophages through a nonclassical secretory pathway. Blood 116:1574-1584. doi:10.1182/blood-2009-11-253815

Core AB, Canali S, Babitt JL. 2014. Hemojuvelin and bone morphogenetic protein (BMP) signaling in iron homeostasis. Front Pharmacol. doi:10.3389/fphar.2014.00104

de Back DZ, Kostova EB, van Kraaij M, van den Berg TK, van Bruggen R. 2014. Of macrophages and red blood cells; a complex love story. Front Physiol $\mathbf{5}$. doi:10.3389/fphys.2014.00009

Dhanakoti SN, Brosnan JT, Herzberg GR, Brosnan ME. 1990. Renal arginine synthesis: Studies in vitro and in vivo. Am J Physiol - Endocrinol Metab 259. doi:10.1152/ajpendo.1990.259.3.e437

Dichtl S, Haschka D, Nairz M, Seifert M, Volani C, Lutz O, Weiss G. 2018. Dopamine promotes cellular iron accumulation and oxidative stress responses in macrophages. Biochem Pharmacol 148:193-201. doi:10.1016/j.bcp.2017.12.001

Drakesmith H, Nemeth E, Ganz T. 2015. Ironing out Ferroportin. Cell Metab 22:777-787. doi:10.1016/j.cmet.2015.09.006

Durinck S, Spellman PT, Birney E, Huber W. 2009. Mapping identifiers for the integration of genomic datasets with the R/ Bioconductor package biomaRt. Nat Protoc 4:1184-1191. 

doi:10.1038/nprot.2009.97

Efron B, Tibshirani R. 2007. On testing the significance of sets of genes. Ann Appl Stat 1:107-129. doi:10.1214/07-AOAS101

Ganz T. 2012. Macrophages and Systemic Iron Homeostasis. J Innate Immun 4:446-453. doi:10.1159/000336423

Gautier L, Cope L, Bolstad BM, Irizarry RA. 2004. Affy - Analysis of Affymetrix GeneChip data at the probe level. Bioinformatics 20:307-315. doi:10.1093/bioinformatics/btg405

Gentleman RC, Carey VJ, Bates DM, Bolstad B, Dettling M, Dudoit S, Ellis B, Gautier L, Ge Y, Gentry J, Hornik K, Hothorn T, Huber W, lacus S, Irizarry R, Leisch F, Li C, Maechler M, Rossini AJ, Sawitzki G, Smith C, Smyth G, Tierney L, Yang JYH, Zhang J. 2004. Bioconductor: open software development for computational biology and bioinformatics. Genome Biol 5:R80. doi:10.1186/gb-2004-5-10-r80

Goeman JJ, Bühlmann P. 2007. Analyzing gene expression data in terms of gene sets: Methodological issues. Bioinformatics 23:980-987. doi:10.1093/bioinformatics/btm051

Goldfarb AN, Freeman KC, Sahu RK, Elagib KE, Holy M, Arneja A, Polanowska-Grabowska R, Gru AA, White Z, Khalil S, Kerins MJ, Ooi A, Leitinger N, Luckey CJ, Delehanty LL. 2021. Iron control of erythroid microtubule cytoskeleton as a potential target in treatment of iron-restricted anemia. Nat Commun 12. doi:10.1038/s41467-021-21938-2

Gonzalez-Roca E, Garcia-Albéniz X, Rodriguez-Mulero S, Gomis RR, Kornacker K, Auer H. 2010. Accurate Expression Profiling of Very Small Cell Populations. PLoS One 5:e14418. doi:10.1371/journal.pone.0014418

Guo M, Härtlova A, Gierliński M, Prescott A, Castellvi J, Losa JH, Petersen SK, Wenzel UA, Dill BD, Emmerich CH, Ramon Y Cajal S, Russell DG, Trost M. 2019. Triggering MSR1 promotes JNK-mediated inflammation in IL-4-activated macrophages. EMBO J 38:115. doi:10.15252/embj.2018100299

Haldar M, Kohyama M, So AY-L, KC W, Wu X, Briseño CG, Satpathy AT, Kretzer NM, Arase $\mathrm{H}$, Rajasekaran NS, Wang L, Egawa T, Igarashi K, Baltimore D, Murphy TL, Murphy KM. 2014. Heme-Mediated SPI-C Induction Promotes Monocyte Differentiation into Iron-Recycling Macrophages. Cell 156:1223-1234. doi:10.1016/j.cell.2014.01.069

Hattangadi SM, Wong P, Zhang L, Flygare J, Lodish HF. 2011. From stem cell to red cell: regulation of erythropoiesis at multiple levels by multiple proteins, RNAs, and chromatin modifications. Blood 118:6258-6268. doi:10.1182/blood-2011-07-356006

Hussell T, Bell TJ. 2014. Alveolar macrophages: plasticity in a tissue-specific context. Nat Rev Immunol 14:81-93. doi:10.1038/nri3600

Irizarry RA. 2003. Exploration, normalization, and summaries of high density oligonucleotide array probe level data. Biostatistics 4:249-264. doi:10.1093/biostatistics/4.2.249

Jd T, Th B. 1968. A simple technique for measuring storage iron concentrations in formalinised liver samples. S Afr J Med Sci 33:9-11.

Jelkmann W. 2011. Regulation of erythropoietin production. J Physiol 589:1251-1258. doi:10.1113/jphysiol.2010.195057

Jha AK, Huang SC-CC, Sergushichev A, Lampropoulou V, Ivanova Y, Loginicheva E, Chmielewski K, Stewart KM, Ashall J, Everts B, Pearce EJ, Driggers EM, Artyomov MN. 2015. Network integration of parallel metabolic and transcriptional data reveals metabolic modules that regulate macrophage polarization. Immunity 42:419-430. doi:10.1016/j.immuni.2015.02.005

JL B, FW H, DM W, Y X, Y S, TA S, JA C, RT C, AL S, CJ W, NC A, HY L. 2006. Bone morphogenetic protein signaling by hemojuvelin regulates hepcidin expression. Nat Genet 38:531-539. doi:10.1038/NG1777

Kawasumi H, Gono T, Kawaguchi Y, Kaneko H, Katsumata Y, Hanaoka M, Kataoka S, Yamanaka H. 2014. IL-6, IL-8, and IL-10 are associated with hyperferritinemia in rapidly progressive interstitial lung disease with polymyositis/dermatomyositis. Biomed Res Int 2014. doi:10.1155/2014/815245

Klei TRL, Meinderts SM, van den Berg TK, van Bruggen R. 2017. From the Cradle to the Grave: The Role of Macrophages in Erythropoiesis and Erythrophagocytosis. Front Immunol 8:73. doi:10.3389/fimmu.2017.00073 
Knutson MD, Oukka M, Koss LM, Aydemir F, Wessling-Resnick M. 2005. Iron release from macrophages after erythrophagocytosis is up-regulated by ferroportin 1 overexpression and down-regulated by hepcidin. Proc Natl Acad Sci 102:1324-1328. doi:10.1073/pnas.0409409102

Koh TJ, DiPietro LA. 2011. Inflammation and wound healing: the role of the macrophage. Expert Rev Mol Med. doi:10.1017/S1462399411001943

Kohyama M, Ise W, Edelson BT, Wilker PR, Hildner K, Mejia C, Frazier WA, Murphy TL, Murphy KM. 2009. Role for Spi-C in the development of red pulp macrophages and splenic iron homeostasis. Nature 457:318-321. doi:10.1038/nature07472

Kuhn V, Diederich L, Keller TCS, Kramer CM, Lückstädt W, Panknin C, Suvorava T, Isakson BE, Kelm M, Cortese-Krott MM. 2017. Red Blood Cell Function and Dysfunction: Redox Regulation, Nitric Oxide Metabolism, Anemia. Antioxid Redox Signal 26:718-742. doi:10.1089/ars.2016.6954

Lee JCM, Gimm JA, Lo AJ, Koury MJ, Krauss SW, Mohandas N, Chasis JA. 2004. Mechanism of protein sorting during erythroblast enucleation: Role of cytoskeletal connectivity. Blood 103:1912-1919. doi:10.1182/blood-2003-03-0928

Liberzon A, Birger C, Thorvaldsdóttir H, Ghandi M, Mesirov JP, Tamayo P. 2015. The Molecular Signatures Database Hallmark Gene Set Collection. Cell Syst 1:417-425. doi:10.1016/j.cels.2015.12.004

Liu S, McConnell SC, Ryan TM. 2013. Erythropoiesis in the Absence of Adult Hemoglobin. Mol Cell Biol 33:2241-2251. doi:10.1128/mcb.01734-12

Lukkarinen M, Näntö-Salonen K, Pulkki K, Aalto M, Simell O. 2003. Oral supplementation corrects plasma lysine concentrations in lysinuric protein intolerance. Metabolism 52:935-938. doi:10.1016/S0026-0495(03)00089-1

Luo B, Gan W, Liu Z, Shen Z, Wang J, Shi R, Liu Yuqi, Liu Yu, Jiang M, Zhang Z, Wu Y. 2016. Erythropoeitin Signaling in Macrophages Promotes Dying Cell Clearance and Immune Tolerance. Immunity 44:287-302. doi:10.1016/j.immuni.2016.01.002

Mauhin W, Habarou F, Gobin S, Servais A, Brassier A, Grisel C, Roda C, Pinto G, Moshous D, Ghalim F, Krug P, Deltour N, Pontoizeau C, Dubois S, Assoun M, Galmiche L, Bonnefont J, Ottolenghi C, de Blic J, Arnoux J, de Lonlay P. 2017. Update on Lysinuric Protein Intolerance, a Multi-faceted Disease Retrospective cohort analysis from birth to adulthood. Orphanet J Rare Dis 12:3. doi:10.1186/s13023-016-0550-8

Moestrup S, Møller H. 2004. CD163: a regulated hemoglobin scavenger receptor with a role in the anti-inflammatory response. Ann Med 36:347-354. doi:10.1080/07853890410033171

Moritz KM, Lim GB, Wintour EM. 1997. Developmental regulation of erythropoietin and erythropoiesis. Am J Physiol Integr Comp Physiol 273:R1829-R1844. doi:10.1152/ajpregu.1997.273.6.R1829

Morris SM. 2002. REGULATION OF ENZYMES OF THE UREA CYCLE AND ARGININE METABOLISM. doi:10.1146/annurev.nutr.22.110801.140547

Murray PJ, Wynn TA. 2011. Protective and pathogenic functions of macrophage subsets. Nat Rev Immunol 11:723-737. doi:10.1038/nri3073

Nairz M, Schleicher U, Schroll A, Sonnweber T, Theurl I, Ludwiczek S, Talasz H, Brandacher G, Moser PL, Muckenthaler MU, Fang FC, Bogdan C, Weiss G. 2013. Nitric oxide-mediated regulation of ferroportin-1 controls macrophage iron homeostasis and immune function in Salmonella infection. J Exp Med 210:855-873. doi:10.1084/jem.20121946

Nemeth E, Ganz T. 2009. The Role of Hepcidin in Iron Metabolism. Acta Haematol 122:7886. doi:10.1159/000243791

Nemeth E, Tuttle MS, Powelson J, Vaughn MB, Donovan A, Ward DM, Ganz T, Kaplan J. 2004. Hepcidin regulates cellular iron efflux by binding to ferroportin and inducing its internalization. Science 306:2090-3. doi:10.1126/science.1104742

Oexle H, Kaser A, Möst J, Bellmann-Weiler R, Werner ER, Werner-Felmayer G, Weiss G. 2003. Pathways for the regulation of interferon- $y$-inducible genes by iron in human monocytic cells. J Leukoc Biol 74:287-294. doi:10.1189/jlb.0802420 
1064

1065

1066

1067

1068

1069

1070

1071

1072

1073

1074

1075

1076

1077

1078

1079

1080

1081

1082

1083

1084

1085

1086

1087

1088

1089

1090

1091

1092

1093

1094

1095

1096

1097

1098

1099

1100

1101

1102

1103

1104

1105

1106

1107

1108

1109

1110

1111

1112

1113

1114

1115

1116

1117

1118
Ogier de Baulny H, Schiff M, Dionisi-Vici C. 2012. Lysinuric protein intolerance (LPI): a multi organ disease by far more complex than a classic urea cycle disorder. Mol Genet Metab 106:12-7. doi:10.1016/j.ymgme.2012.02.010

Oldenborg P-A. 2000. Role of CD47 as a Marker of Self on Red Blood Cells. Science (80- ) 288:2051-2054. doi:10.1126/science.288.5473.2051

Palacín M, Borsani G, Sebastio G. 2001. The molecular bases of cystinuria and lysinuric protein intolerance. Curr Opin Genet Dev 11:328-335. doi:10.1016/S0959437X(00)00198-2

Palacín M, Nunes V, Font-Llitjós M, Jiménez-Vidal M, Fort J, Gasol E, Pineda M, Feliubadaló L, Chillarón J, Zorzano A. 2005. The Genetics of Heteromeric Amino Acid Transporters. Physiology 20:112-124. doi:10.1152/physiol.00051.2004

Park SY, Kim IS. 2017. Engulfment signals and the phagocytic machinery for apoptotic cell clearance. Exp Mol Med. doi:10.1038/emm.2017.52

Parto K, Maki J, Pelliniemi LJ, Simell O. 1994. Abnormal pulmonary macrophages in lysinuric protein intolerance: Ultrastructural, morphometric, and x-ray microanalytic study. Arch Pathol Lab Med 118:536-541.

Patel BN, Dunn RJ, Jeong SY, Zhu Q, Julien JP, David S. 2002. Ceruloplasmin regulates iron levels in the CNS and prevents free radical injury. J Neurosci 22:6578-6586. doi:10.1523/jneurosci.22-15-06578.2002

Perkins CP, Mar V, Shutter JR, Castillo J Del, Danilenko DM, Medlock ES, Ponting IL, Graham M, Stark KL, Zuo Y, Cunningham JM, Bosselman RA. 1997. Anemia and perinatal death result from loss of the murine ecotropic retrovirus receptor mCAT-1. Genes Dev 11:914-925. doi:10.1101/gad.11.7.914

Pollard JW. 2009. Trophic macrophages in development and disease. Nat Rev Immunol 9:259-270. doi:10.1038/nri2528

Popova EY, Krauss SW, Short SA, Lee G, Villalobos J, Etzell J, Koury MJ, Ney PA, Chasis JA, Grigoryev SA. 2009. Chromatin condensation in terminally differentiating mouse erythroblasts does not involve special architectural proteins but depends on histone deacetylation. Chromosom Res 17:47-64. doi:10.1007/s10577-008-9005-y

Posey JE, Burrage LC, Miller MJ, Liu P, Hardison MT, Elsea SH, Sun Q, Yang Y, Willis AS, Schlesinger AE, Bacino CA, Lee BH. 2014. Lysinuric protein intolerance presenting with multiple fractures. Mol Genet Metab Reports 1:176-183. doi:10.1016/j.ymgmr.2014.03.004

R Core T. 2019. R: A language and environment for statistical computing. R Foundation for Statistical Computing. Vienna, Austria. https://www.r-project.org/.

Rajantie J, Simell O, Rapola J, Perheentupa J. 1980. Lysinuric protein intolerance: A twoyear trial of dietary supplementation therapy with citrulline and lysine. J Pediatr 97:927932. doi:10.1016/S0022-3476(80)80422-7

Recalcati S, Locati M, Gammella E, Invernizzi P, Cairo G. 2012. Iron levels in polarized macrophages: Regulation of immunity and autoimmunity. Autoimmun Rev. doi:10.1016/j.autrev.2012.03.003

Ritchie ME, Phipson B, Wu D, Hu Y, Law CW, Shi W, Smyth GK. 2015. Limma powers differential expression analyses for RNA-sequencing and microarray studies. Nucleic Acids Res 43:e47. doi:10.1093/nar/gkv007

Rosário C, Zandman-Goddard G, Meyron-Holtz EG, D'Cruz DP, Shoenfeld Y. 2013. The Hyperferritinemic Syndrome: macrophage activation syndrome, Still's disease, septic shock and catastrophic antiphospholipid syndrome. BMC Med 11:185. doi:10.1186/1741-7015-11-185

Rotoli BM, Barilli A, Visigalli R, Ferrari F, Dall'Asta V. 2020. y+LAT1 and y+LAT2 contribution to arginine uptake in different human cell models: Implications in the pathophysiology of Lysinuric Protein Intolerance. J Cell Mol Med 24:921-929. doi:10.1111/jcmm.14801

Sebastiani G, Wilkinson N, Pantopoulos K. 2016. Pharmacological targeting of the hepcidin/ferroportin axis. Front Pharmacol 7:1-11. doi:10.3389/fphar.2016.00160

Shima Y, Maeda T, Aizawa S, Tsuboi I, Kobayashi D, Kato R, Tamai I. 2006. HEMATOPOIESIS L -arginine import via cationic amino acid transporter CAT1 is 
essential for both differentiation and proliferation of erythrocytes. Blood 107:1352-1356. doi:10.1182/blood-2005-08-3166.Reprints

Smyth GK. 2004. Linear models and empirical bayes methods for assessing differential expression in microarray experiments. Stat Appl Genet Mol Biol 3. doi:10.2202/15446115.1027

Soares MP, Hamza I. 2016. Macrophages and Iron Metabolism. Immunity. doi:10.1016/j.immuni.2016.02.016

Stienstra R, Netea-Maier RT, Riksen NP, Joosten LAB, Netea MG. 2017. Specific and Complex Reprogramming of Cellular Metabolism in Myeloid Cells during Innate Immune Responses. Cell Metab. doi:10.1016/j.cmet.2017.06.001

Swartz KL, Wood SN, Murthy T, Ramirez O, Qin G, Pillai MM, Rao S, Minella AC. 2017. E2F-2 Promotes Nuclear Condensation and Enucleation of Terminally Differentiated Erythroblasts. Mol Cell Biol 37. doi:10.1128/mcb.00274-16

Theurl I, Hilgendorf I, Nairz M, Tymoszuk P, Haschka D, Asshoff M, He S, Gerhardt LMS, Holderried TAW, Seifert M, Sopper S, Fenn AM, Anzai A, Rattik S, McAlpine C, Theurl M, Wieghofer P, Iwamoto Y, Weber GF, Harder NK, Chousterman BG, Arvedson TL, McKee M, Wang F, Lutz OMD, Rezoagli E, Babitt JL, Berra L, Prinz M, Nahrendorf M, Weiss G, Weissleder R, Lin HY, Swirski FK. 2016. On-demand erythrocyte disposal and iron recycling requires transient macrophages in the liver. Nat Med 22:945-951. doi:10.1038/nm.4146

Torrents D, Mykkänen J, Pineda M, Feliubadaló L, Estévez R, de Cid R, Sanjurjo P, Zorzano A, Nunes V, Huoponen K, Reinikainen A, Simell O, Savontaus M-LL, Aula P, Palacín M, Cid Rafael de, Sanjurjo P, Zorzano A, Nunes V, Huoponen K, Reinikainen A, Simell O, Savontaus M-LL, Aula P, Palacín M, de Cid R, Sanjurjo P, Zorzano A, Nunes V, Huoponen K, Reinikainen A, Simell O, Savontaus M-LL, Aula P, Palacín M. 1999. Identification of SLC7A7, encoding $y+L A T-1$, as the lysinuric protein intolerance gene. Nat Genet 21:293-296. doi:10.1038/6809

Weiss G, Schaible UE. 2015. Macrophage defense mechanisms against intracellular bacteria. Immunol Rev 264:182-203. doi:10.1111/imr.12266

Wu D, Lim E, Vaillant F, Asselin-Labat ML, Visvader JE, Smyth GK. 2010. ROAST: Rotation gene set tests for complex microarray experiments. Bioinformatics 26:2176-2182. doi:10.1093/bioinformatics/btq401 